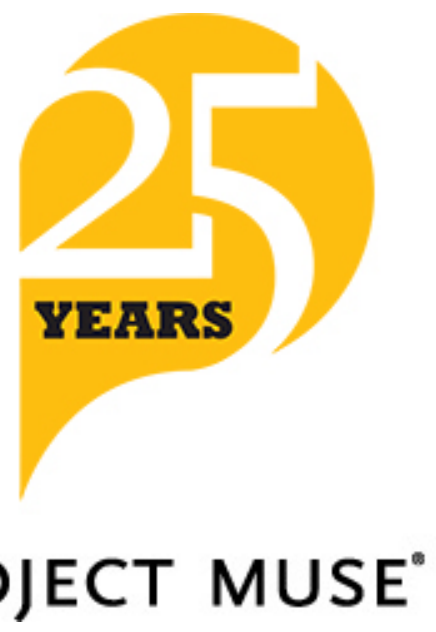

PROJECT MUSE*

The genesis and typology of correlatives

Oleg Belyaev, Dag Haug

Language, Volume 96, Number 4, December 2020, pp. 874-907 (Article)

Published by Linguistic Society of America

DOI: https://doi.org/10.1353/lan.2020.0065

$\Rightarrow$ For additional information about this article https://muse.jhu.edu/article/775368 


\section{THE GENESIS AND TYPOLOGY OF CORRELATIVES}

\section{Oleg Belyaev}

\section{Lomonosov Moscow State University and Pushkin State Russian Language Institute}

DAg HAUG

University of Oslo

This article argues for a new theory of the origin of wH-correlatives from indefinite uses of wHwords in paratactic or asyndetic conditionals. We show that this theory predicts a generalization that has so far gone unnoticed: WH-based correlatives always have a universal reading; they may also have a definite reading, which may be morphologically marked. This is in contrast to correlatives where the relativizer originates from a demonstrative element: these always have a definite reading and may also have a universal reading. We demonstrate the validity of this generalization on a data set containing thirty-eight correlative structures from thirty-two languages, that is, all of the correlative structures that are sufficiently well described in the literature.*

Keywords: correlatives, relative clauses, indefinite pronouns, historical syntax, grammaticalization, DRT

1. Introduction. Crosslinguistically, correlatives are a common strategy for relativization found in languages of West Africa, the Indian subcontinent, Australia, South America, and across Eurasia. ${ }^{1}$ Some examples are shown in $1-4 .^{2}$

(1) Bambara (Mande > Niger-Congo)

[ce min ye muru san], n ye o ye

man REL PST knife buy I PST him see

'The man who bought the knife, I saw him.'

(Givón 2009:98)

* Earlier versions of this work have been presented at Sinn und Bedeutung 19 (2014), Diachronic Generative Syntax 17 (2015), and the 22nd International Conference on Historical Linguistics (2015). We are grateful to the participants at those conferences for their questions and comments. We also express our deep gratitude to Mary Dalrymple, Regine Eckardt, Maria Kholodilova, Tatiana Nikitina, Andrej Sideltsev, Rob Truswell, Igor Yanovich, two anonymous Language referees, and associate editor David Willis for their insightful remarks and additions to earlier drafts of this article. We also specifically thank the following people for their consultations on individual languages and examples: Sangyub Baek (Tungusic, Sinitic), Yulia Galyamina (Ket), Stefan Georg (Ket), Thomas Lehmann (Tamil), Andrey Nefedov (Ket), and Anton Zimmerling (Old Czech). Oleg Belyaev's research has been supported by the Russian Science Foundation, project no. 18-18-00462.

${ }^{1}$ We restrict ourselves to correlatives that relativize on individuals, excluding such constructions as the 'comparative correlative'.

2 The glosses follow the Leipzig glossing rules (https://www.eva.mpg.de/lingua/resources/glossing-rules .php), with the following additional abbreviations: ACP.POS: positive completive (French accompli), ADD: additive, ANIM: animate, AOR: aorist, CONJ: conjunction, ESS: essive, EXST: existential, HAB: habitual, HUM: human, ILL: illative, IN: inessive, INACP.POS: positive incompletive (French inaccompli), INANIM: inanimate, IQ: indirect question marker, OPT: optative, POSTP: postposition, PTCL: particle, PV: preverb, SUPER: marker of location above landmark, wH: interrogative. The glossing of the source (where relevant) is largely preserved, with two exceptions. First, abbreviations are unified in accordance with the Leipzig rules and the list above. Second, for consistency in designating the relativization marking, the glosses 'which', 'who', 'what', and 'whose' have been replaced by REL, REL.ANIM, REL.INANIM, and REL.POSS, respectively.

The labels WH and DEM in example headings indicate the origin of the relativization marker in correlatives: interrogative or demonstrative, respectively. Typological data that are crucial for the main point of the article are provided in a separate online supplement, available at http://muse.jhu.edu/resolve/112. 
(2) Ossetic (Iranian > Indo-European)

[didinక̌-ət3 so čəžg-3n ba-lsvar kot:-aj ], fet:-on

flower-PL REL girl-DAT PV-present do-PST.2SG see.PFV-PST.1SG

wəj fəd-ə

that [GEN] father-GEN

'The girl you gave flowers to, I saw her father.'

[WH]

(3) Hungarian (Finno-Ugric > Uralic)

[Akit szeret Mari], azt meghívta a buliba.

(Belyaev 2014)

REL.ANIM:ACC.SG loves Mari that:ACC.SG invited the party:ILL

'Who(ever) Mari loves, she invited to the party.' (Lipták 2008, ex. 17)

(4) Kryz (Lezgian > East Caucasian)

hal-id q'ay-cu a-d an q'ay-i!

[WH]

REL.POSS-HUM die-PRF.F 3-HUM ADD die-OPT

'Whose (wife?) died, let him die as well!'3

(Authier 2009:380)

In some of the literature, especially in typology, there is a tendency to treat correlatives as a somewhat marginal or 'exotic' type of relativization, as exemplified by the WALS map 90E (Dryer 2013). As seen from our sample of languages in the online supplement and from the list given in Lipták 2009b:10-11, this is in fact not the case: correlatives are found in a wide variety of languages of different genetic backgrounds and structural types in a number of diverse linguistic areas. The misconception that correlatives are rare stems from the fact that in many languages, these clauses are described in different terms or exist as a secondary strategy alongside another type of relativization.

The latter fact is significant. Unlike other relative clause types, which are generally aligned with other typological parameters (e.g. prenominal relative clauses are typical of OV languages, postnominal of VO, etc.), correlatives seem to be a strategy that can develop in virtually any language. Intuitively, what makes this possible is their apparently simple, nonembedded, virtually juxtapositional configuration; in fact, correlatives have been assumed to be one of the initial stages, close to parataxis, in the grammaticalization of relative clauses in some of the literature (Givón 2009:98-99, Hopper \& Traugott 2003:199-200). However, while claims like this are made quite often, there have been few specific proposals on how particular types of correlatives can actually grammaticalize.

Similarly, although correlatives have been discussed quite extensively in the literature, fairly little is known about how they vary semantically across languages. The assumption underlying much of the research seems to be that although there may be variation in the details, the basic structure and meaning of correlatives are the same across languages.

It is true that some things do appear to be constant. For example, to the best of our knowledge, correlatives always have a MAXIMALIzING semantics (Grosu \& Landman 1998). However, it is well known from the literature that maximalization may be realized as a DEFINITE reading, as in 1 and 2, or as a UNIVERSAL reading, as in $3 .{ }^{4}$ It is less commonly noticed that not all languages with correlatives allow both readings. This yields one parameter of variation: although correlatives always have maximalizing readings, languages can allow maximalization to be realized as definite readings, or as universal readings, or as both.

\footnotetext{
${ }^{3}$ Original translation: Celui de qui elle est morte, qu'il meure aussi!

${ }^{4}$ Sometimes, as in 4, it can be hard to tell the two readings apart because if the predicate ' $x$ 's wife is dead' is uniquely satisfied, the universal and the definite readings will be very close. We return to this point in $\S 4.5$.
} 
Another parameter of variation concerns the morphological makeup of the relativizers in correlative structures. Correlative clauses typically contain an NP that is made up of a relativizer plus an optional nominal head. In some languages the relativizer is originally some sort of definite determiner, most often a demonstrative pronoun; this is the case with Bambara min in 1. In other languages the relativizer is originally an interrogative (WH-word); this is the case with Ossetic sa in 2. Moreover, many of these languages display an interrogative-indefinite ambiguity (Gärtner 2009), whereby the WH-word found in correlatives is used outside of correlatives not only as an interrogative, but also as an indefinite. This is the case, for example, with Kryz $t i$ 'who' (oblique stem hal-), seen in 4.

In this article, we argue that these two parameters of variation are interrelated due to different diachronic pathways that lead to the two structural types of correlatives. The structure of our argument is essentially abductive: we propose a new theory for the origin of WH-correlatives and motivate it, but we cannot actually trace this evolution in the texts. Instead we argue that it should be adopted because it offers the best account of a previously unnoticed typological generalization (5), which clearly demands an explanation.

(5) a. A wH-based correlative always has a universal reading; it may also have a definite reading, which may be morphologically marked.

b. A DEM-based correlative always has a definite reading; it may also have a universal reading, which may (or must?) be morphologically marked.

In other words, the universal reading is basic for wH-based correlatives, and the definite reading is basic for DEM-based correlatives. Moreover, while wH-correlatives can have the universal reading without any additional marking, all of the DEM-based correlatives in our sample that can take on the universal reading require extra morphological marking to do so.

The idea that there are two different kinds of correlatives is not new. ${ }^{5}$ The contribution of this article is to show that the distinction between the two kinds of correlatives is not arbitrary but depends on their morphological makeup, and to offer a diachronic account of why this is so.

Although the primary goal of the article is to elucidate the typology and diachrony of correlative constructions, we do believe that there is a wider methodological lesson to be learned. In particular, our study shows that a semantic distinction that has been noticed in the literature, but was never given much prominence, is actually key to understanding how correlatives evolve. Although we do not provide detailed formalization of the semantics, our article belongs in the tradition of formal diachronic semantics (Eckardt $2006,2011)$ and brings more evidence that structural semantic change is crucial to understanding grammaticalization processes. Furthermore, our work has implications for the synchronic study of correlatives, as most current work assumes that the definite reading is basic and the universal reading derived by an additional operator.

The structure of the article is as follows. First, we provide background on correlative structures and their interpretations $(\S 2)$. Then, we show in $\S 3$ that the theory of paratactic origin that is generally assumed for DEM-correlatives does not seem to be easily transferable to wH-correlatives. In $\S 4$ we show how wH-correlatives can instead arise from (ordinary, paratactic, or asyndetic) conditional structures. The different origins of

\footnotetext{
${ }^{5}$ For example, Demirok (2017) argues that correlatives in Turkish are 'conditional-like' and different from correlatives in Hindi. We return to the link between conditional structures and universal readings of conditionals below.
} 
the two correlative types predict different basic meanings for the structures, and we show that these predictions are borne out in $\S 5$. In $\S 6$ we conclude.

2. Correlatives AND THEIR READINGS.

2.1. Correlative Structures. We define a correlative structure as in 6 . $^{6}$

(6) A correlative structure consists of two clauses, the correlative clause and the matrix clause, where

(i) a noun phrase containing a relativizer occurs in the correlative clause ${ }^{7}$

(ii) a noun phrase anaphorically related to the first one occurs in the matrix clause;

(iii) the correlative clause is wholly to the left of the matrix clause. ${ }^{8}$

We refer to the correlative (dependent) clause as $\mathrm{S}_{\text {rel }}$ and the matrix clause as $\mathrm{S}_{\text {mat }}$, and their respective anaphorically linked positions as $\mathrm{NP}_{\text {rel }}$ and $\mathrm{NP}_{\text {mat. }}$ It is crucial that both of these positions are full NPs and that either or both may contain a lexical head. Moreover, $\mathrm{NP}_{\text {rel }}$ obligatorily contains a lexical item that we refer to as a RELATIVIZER, ${ }^{9}$ and it is this element that gives rise to the distinction we mentioned in the introduction: in $\mathrm{WH}^{-}$ based correlatives the relativizer either is identical to an interrogative (a 'bare interrogative') that typically can also be used as an indefinite, or is morphologically derived from an interrogative (sometimes identical to an indefinite pronoun). In DEM-based correlatives it is typically a demonstrative pronoun, though it can also be another definite determiner, a personal pronoun, or even zero, in languages where unmarked NPs can be understood as definites. ${ }^{10}$

Assuming for the exposition here that $\mathrm{NP}_{\text {rel }}$ is adjoined to $\mathrm{S}_{\text {rel }}$ as a means of syntactic relativization (this will vary across languages), a correlative structure such as 2 will schematically look like 7 . Note that we are using $\mathrm{S}$ as a pretheoretical label for clausal categories and are making no commitment as to the concrete syntactic category of either the correlative clause or the matrix, except that it is clausal rather than nominal.

(7)

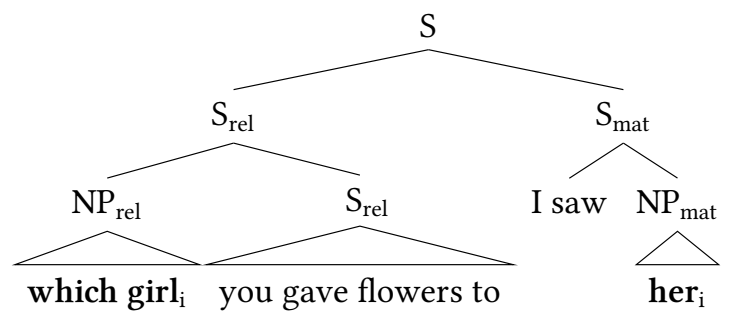

\footnotetext{
${ }^{6}$ Notice that we focus on nominal correlatives because we believe these define the core of the correlative construction, although it can be generalized to any kind of entity that can be picked up anaphorically (e.g. 'when we left, then it was cold').

${ }^{7}$ In some languages, correlatives can also involve multiple NPs linked to multiple correlates; for simplicity, our definition includes only simple correlatives, but it can be easily generalized to multiple ones. Constructions with multiple NPs sometimes have different semantics; see, for example, the Ossetic data in the online supplement.

${ }^{8}$ In certain languages, right-detached structures that have been labeled as 'correlative' actually display different properties from 'true' correlatives. For example, Srivastav (1991) has shown that Hindi right-peripheral relative clauses should more properly be treated as externally headed adnominal constructions with the subordinate clause right-dislocated. Therefore, we limit ourselves to left-peripheral examples in order to avoid possible misinterpretations.

${ }^{9}$ This is merely a label for that lexical item and does not imply that there is necessarily any syntactic operation of relativization; see below. The marker need not be the same as used in other relativization strategies the language may have, but it must be consistently used in correlative structures.

${ }^{10}$ In such languages, unmarked NPs will typically be ambiguous between a definite and an indefinite reading. But given the conspicuous lack of correlative structures where $\mathrm{NP}_{\text {rel }}$ derives from an unambiguous, nonWH indefinite, we are justified in taking an ambiguous $\mathrm{NP}_{\text {rel }}$ to be a definite.
} 
There are various proposals as to how a surface structure such as 7 should be understood, but these do not matter for our account, which mainly concerns semantics. ${ }^{11}$ What does matter is that the same surface string as in 7 can also arise from a different structure, which is not a correlative and hence not relevant for this article, namely through the leftward displacement of an internally headed (or free) relative clause, which is then resumed in the main clause. This yields a structure such as that in 8. (Again, the details of the structure do not matter; only the fact that the dislocated element is nominal is important.)

(8)

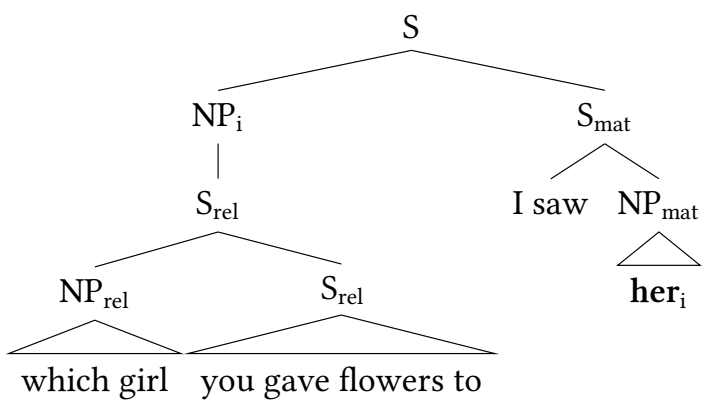

Following de Vries (2002:46) we refer to such structures as 'hanging relatives'. ${ }^{12}$ As observed by Keenan (1985:165), it may be hard in practice to distinguish between true correlatives and such hanging relatives. Nevertheless, there is at least one important structural difference, namely the nominal nature of the left-dislocated element. Crucially, in 8 the relative clause is nominal and is resumed in the main clause. Therefore, the analysis in 8 is plausible only if the language in question has left dislocation with resumption. ${ }^{13}$ This is the case, for example, in German, which means that it is plausible to analyze a structure such as 9 as a hanging relative rather than a true correlative structure.

(9) German (Germanic > Indo-European)

Wer immer strebend sich bemüht, den können

REL:nom always striving REFL strive:PRS.3sG him:ACC can:PRS.3PL

wir erlösen.

we:NOM redeem:INF

'Who strives always to the utmost, we can redeem him.'

By contrast, it is implausible to argue that, for example, the Ossetic correlative in 2 is a hanging relative, because in this language, relative clauses cannot actually occur in argument positions by themselves, and left dislocation with resumption by demonstrative NPs is a marginal strategy. Ossetic is by no means isolated in not allowing an analysis of correlatives as hanging relatives: de Vries (2002:App. II, table 4) lists eight languages where correlatives are the ONLY strategy for relativization (Ossetic is not in his sample).

A further argument that correlative structures and free relative structures are distinct comes from WH-in-situ languages. As argued by Demirok (2017), free relatives are

\footnotetext{
11 The syntactic issue has mostly been explored for Hindi correlatives, and there are two competing analyses. Srivastav (1991) proposed that $\mathrm{S}_{\text {rel }}$ is base-generated in the left-peripheral position (adjoined to $\mathrm{S}_{\text {mat }}$ ), whereas Bhatt (2003) argues that $\mathrm{S}_{\text {rel }}$ originates as an adjunct to $\mathrm{NP}_{\text {mat }}$ and undergoes (optional) movement to the left periphery.

12 De Vries (2002) actually uses 'hanging FREE relatives', but we want a term that also covers structures where the fronted relative clause actually has an internal head, as in 8.

${ }^{13}$ Furthermore, given that the relative clause is an NP, we could expect it to occur nondislocated in argument positions, but this is sometimes restricted, for example, by case-matching criteria.
} 
exceedingly rare in WH-in-situ languages - the only reported case seems to be Tsez (Polinsky 2015). By contrast, correlatives do occur in WH-in-situ languages, for example, in Turkish and East Caucasian. Whatever the explanation of the asymmetry, ${ }^{14}$ this constitutes a clear argument that the two structures are distinct.

In sum, we conclude, contra Cinque (2012), that correlatives are a separate kind of relative clause formation that cannot be reduced to other kinds of relativization. In particular, correlatives are syntactically distinct from other relative clauses, even their closest kin, the hanging relatives.

2.2. Maximalization And the SEmantics of CORRelatives. Traditionally, relative clauses are categorized as either restrictive or nonrestrictive. However, as mentioned in the introduction, there is a third type of relative clause, which Grosu and Landman (1998) call 'maximalizing relatives'. ${ }^{15}$ The hallmark of a maximalizing relative clause is that it refers to the MAXIMAL set of entities that satisfy the relative clause property. Moreover, in the case of maximalizing constructions, the relative clause property also includes the head noun, which is interpreted (and typically realized; see exs. 1-2) inside the relative clause.

An example will make the difference clear. In an ordinary restrictive relative structure, the relative clause denotes the set of individuals that satisfy the predicate created by abstracting over the gap. This set is then intersected with the denotation of the head noun, which is also a set. That is, which you gave flowers to denotes the set of individuals that you gave flowers to, girl denotes the set of girls, and girl which you gave flowers to denotes the intersection of these sets, that is, the set of $x$ such that $x$ is a girl and you gave flowers to $x$. Finally, a determiner may apply to this set to yield a generalized quantifier A/Every/The girl which you gave flowers to.

In maximalizing relatives, Grosu and Landman (1998) argue, things proceed differently. The correlative clause in 2, for example, denotes the set of girls you gave flowers to. Crucially, an operation of maximalization applies to this meaning. Maximalization is an operation that maps a set to the singleton set containing its maximal member if there is one (Grosu \& Landman 1998, ex. 100b). If the head noun is singular, this gives us uniqueness. For example, if there is only one girl, Catherine, such that you gave flowers to her, then the relative clause will denote the set $\{$ catherine $\}$, and maximalization will leave this unchanged as \{catherine $\}$. If there are two girls, Catherine and Anne, such that you gave flowers to them, the relative clause will denote the set \{catherine, anne\}, which has no maximal element. This means that 2 cannot describe such a situation, which is reflected in the definite singular the girl in the English translation; but notice that Ossetic has no marker of definiteness.

If, by contrast, the head noun is plural, the relative clause will range over plural individuals. So if there are three girls, Catherine, Anne, and Jane, such that you gave flowers to them, the relative clause will denote the set $\{$ catherine $\oplus$ anne, catherine $\oplus$ jane, anne $\oplus$ jane, catherine $\oplus$ anne $\oplus$ jane $\},{ }^{16}$ where $\oplus$ is a group-forming operator. Maximalization will yield \{catherine $\oplus$ anne $\oplus$ jane , that is, the unique maximal individual

\footnotetext{
${ }^{14}$ Demirok (2017) argues that correlatives, unlike free relatives, do not necessarily involve relativization at all. If true, that resonates well with the diachronic story of wH-based correlatives proposed in this article.

${ }^{15}$ Several relative structures are maximalizing: Grosu and Landman (1998) discuss degree relatives, free relatives, internally headed relatives, and correlatives. There may be some crosslinguistic variation, since there are languages where free and internally headed relatives are not maximalizing, but as far as is known, correlatives are always maximalizing in the languages where they are found.

${ }^{16}$ On a so-called inclusive view of the plural, the plural will also include atomic individuals in its extension, but this does not affect our point here.
} 
that satisfies the predicate. So we get uniqueness here too, and the sentence cannot mean 'I saw some girls that you gave flowers to'. If we want to express the indefinite (singular or plural) reading 'I saw a girl/some girls that you gave flowers to', it must be expressed 'The girls you gave flowers to, I saw one/some of them', where the correlative clause is again maximal and the indefiniteness comes from the partitive 'one/some of them' in the matrix clause.

On the face of it, 3 constitutes an exception to maximalization. It clearly does not involve reference to a contextually unique person who Mari loves. Instead it generalizes over all persons Mari loves. This is what maximalization would predict if the head noun was plural, since the relative clause should then refer to the maximal plurality containing all persons. But in 3, the interrogative and the main clause demonstrative are singular, and we still get a generalization over the set of all persons.

One way to analyze this involves a habitual operator (Dayal 1995) that - so the story goes - introduces quantification over situations involving one individual, so that maximalization is preserved inside each situation. For Hindi, which was analyzed by Dayal, this is plausible because universal readings are licensed only under habitual tenses that arguably instantiate the operator that quantifies over situations. On this way of looking at things, then, the definite reading is basic and the universal meaning derived.

However, this approach will not work for Hungarian; 3 contains no generic operator and cannot, in fact, be a generic sentence because it is episodic and describes a particular event. Instead it seems that the correlative structure directly involves quantification. And there is in fact an alternative account of correlatives that derives the universal reading from a conditional structure. This goes back to at least Andrews (1975:97), who suggested the following algorithm for translating a correlative clause into English: replace the WH-expression(s) with indefinite(s) and recast the relative clause as a conditional. Applied to 3, this would yield 10.

(10) If Mari loves a person, she invited him/her to the party.

Bittner (2001) spells out Andrews's intuition in formal detail and achieves a semantic representation that is ambiguous between a correlative and a conditional reading, depending on whether the adjoined clause is taken to introduce an individual or a possibility as the topical discourse referent. ${ }^{17}$

In sum, then, we have two different readings of correlatives, which we can think of as different instantiations of maximalization: the definite and the universal readings. But there are many contexts where we cannot tell the two readings apart. In generic sentences, definiteness can be understood relative to each situation that the generic operator quantifies over. Moreover, plural predicates and predicates that are uniquely satisfied also yield similar truth conditions for both readings, as we will see in $\S 4.5$. We will later see that these contexts provide plausible opportunities for reanalysis.

3. EARLIER RESEARCH. In this section, we provide an overview of prior approaches to the diachronic development of correlatives from clauses containing demonstrative and interrogative elements. We show that existing approaches to the evolution of interrogative-based correlatives are inadequate and fail to explain the observed semantic distribution of the structural types of correlative clauses.

\footnotetext{
${ }^{17}$ Bittner (2001) goes on to argue that this is the correct analysis of the so-called 'adjoined relative clause' in Australian languages (Hale 1976). Since it is unclear whether these are in fact correlative clauses (see Nordlinger 2006), we do not discuss them further here.
} 
3.1. Dem-BASED CORRElatives From PARATAXIs. There is consensus in the literature that demonstrative-based correlatives derive from paratactic structures, as indicated in 1. For example, Givón (2009:98) takes constructions like 1 in Bambara to have arisen as in 11 .

(11) That man bought the knife. I saw him. $\rightarrow$ The man who bought the knife, I saw him.

While the development of relative clause markers from demonstratives has been rather well known at least since Paul's (1909:300-301) discussion of the evolution from demonstratives to relatives in German (der), the case of Bambara is different because the result is a correlative construction. Therefore, we briefly explain how such a change might have come about.

It seems clear that the relative markers in Mande correlatives arose from demonstratives. In Bambara, the relative marker min is in fact completely homonymous with the demonstrative. ${ }^{18}$ In the closely related Kita Maninka, mín is also clearly of demonstrative origin (Creissels 2009: §39-40). In Mande languages of other branches, such as Kla-Dan and Wan, the correlative construction is indistinguishable from the juxtaposition of two clauses with demonstratives except for the tone marking (Makeeva 2013, Nikitina 2012). As expected from the hypothesis of a paratactic origin of the correlative construction in these languages, the primary interpretation of relative clauses is a definite one; the universal reading, if available at all, has to be explicitly marked by the conjunction 'if' (Creissels 2009:§61). All of this seems to confirm the idea expressed by Givón and other scholars that correlatives in Mande represent a relatively recent grammaticalization from clause juxtaposition. Demonstrative-based correlatives in other languages can be assumed to follow the same path, at least insofar as their demonstrative provenance is conclusively proven. As we will see, these languages allow the universal reading only when there is additional material present, such as a conditional marker or generic/habitual morphology.

3.2. Wh-BASED CORRElatives. For Wh-based correlatives, the picture is much more unclear. Partly this is because of the interrogative-indefinite affinity: as mentioned in the introduction, $\mathrm{WH}$-words in languages with $\mathrm{WH}$-based correlatives typically function as both interrogatives and indefinites (in addition to their role in correlatives), at least in certain contexts. In particular, this is true of the early Indo-European languages, which have received the most attention in prior work. For this reason, there are two competing hypotheses about the rise of correlatives in Indo-European, one starting from indefinites and the other starting from interrogatives.

The indefinite hypothesis seems first to have been proposed for Latin correlative structures by Kroll (1910), ${ }^{19}$ with examples such as 12 .

\footnotetext{
${ }^{18}$ Lehmann (2015:57) states that the relative marker is actually derived from an interrogative, but the demonstrative-based origin is in fact rather firmly established based on both the data of Bambara and evidence from across the Mande languages (Denis Creissels, p.c.).

${ }^{19}$ Kroll mentions that the idea had already been foreshadowed ('gelegentlich angedeutet') by other authors, which we have been unable to check.
} 
(12) Latin (Italic > Indo-European)

[paries qui est propter viam ], in eo

[WH] wall:NOM.SG REL.NOM.SG is:PRS.3SG near road:ACC.SG in that:ABL.SG pariete medio ostiei lumen aperito wall:ABL.SG middle:ABL.SG doorway:GEN.SG gap:ACC.SG open:IMP.3sG 'He shall open a gap for a doorway in the middle of the wall that is near the road.'

( $\leftarrow$ 'Some wall is near the road; in that wall he shall open a gap for a doorway.')

(Corpus Inscriptionum Latinarum I.577 I.9)

The same origin was proposed for Hittite correlative clauses (without mention of Kroll) by Hahn $(1946,1949)$, and from there it made it to much of the modern literature. According to this theory we expect a definite reading for correlatives. Unlike in DEM-based correlatives, the reason is no longer that $\mathrm{NP}_{\text {rel }}$ is inherently definite - it clearly is not, if the relative derives from an indefinite. Rather, it is the anaphoric mechanism that ensures maximalization. As pointed out by Kadmon (1990), anaphora is inherently exhaustive.

(13) Leif has a chair.

(Leif may have several chairs.)

(14) Leif has a chair. It is in the kitchen.

(Leif has only one chair.)

Similarly, we correctly expect the relative clause in 12 to refer to the UNIQUE wall that is near the road, not just some wall that is near the road; even if there is no overt marking of definiteness in the correlative clauses, the anaphoric uptake in the matrix clause yields this effect.

The exhaustivity of anaphora was exploited by Brasoveanu (2008) to get a maximalizing semantics for correlatives. But notice that the maximalization we get is of the definite kind: there is no straightforward way that the postulated original meaning of 12 would yield a universal reading. So the expectation would be that the definite reading is basic and the universal reading requires extra machinery.

An additional problematic assumption of this hypothesis is that WH-words were ambiguous between indefinite and interrogative readings in plain declaratives in ProtoIndo-European. While this is often assumed, the comparative evidence points to the indefinite reading being restricted to certain embedded contexts (Haug 2016). We return to this point later.

The alternative theory assumes that the relative pronouns of Hittite and Latin arise from the interrogative use of $*^{*} k^{w i} /{ }^{*} k^{w} O-$. The pathway from indirect questions to relative clauses has been sketched by Haudry (1973:150) and Heine and Kuteva (2006:209), and is shown in 15 .

(15) a. constituent question: Who came?

b. indirect question: I don't know who came.

c. indirect question reanalyzable as headless relative clauses: You also know who came.

d. headed relative clauses: Do you know the woman who came?

This approach is standard in current literature on the development of postnominal relative clauses with interrogatives and has been assumed in more recent publications such as Givón 2009:117ff. and Hendery 2012:48ff. Indeed, it has proved to be robust in describing and explaining the development of this type of relative clause in the history of many languages: even contact-induced change seems to generally follow the same scenario; see for example the case study of Tuscarora (Iroquoian) in Mithun 2012.

However, this approach clearly does not yield correlative structures with a matrix correlate, nor the position of correlatives before their matrix clauses. There are attempts 
in the early literature to derive the correlative structures by assuming rhetorical questions or pieces of discourse with interruption: '-A man ... -Who? -He was in Rome. He is dead' (Wegener 1874:25). Such reconstructions are not very credible. ${ }^{20}$

Most modern proponents of the interrogative theory have been less explicit about the source structures. But it seems clear that they must assume the standard pathway from constituent questions to headless relative clauses, that is, $15 \mathrm{a}-\mathrm{c}$ above, and then assume that instead of (or perhaps in addition to) taking the step to create headed relative clauses, the reanalyzed relative clause was left-dislocated and resumed in the matrix to yield a hanging free relative as in 16 , which could potentially be reanalyzed as a correlative structure.

(16) Who came, you also know him.

This view is clearly committed to the claim that a language which develops correlatives in this way already has relative clauses (either headless or internally headed ones) and a mechanism of left dislocation with resumption in the matrix. Moreover, the source relative clause must be an NP - this is standardly assumed for headless and internally headed relative clauses and also required to get anaphoric resumption in the matrix clause. As such, this explanation is problematic for languages where correlatives are the only means of relativization, unless it can be made plausible that the language had other strategies when correlatives arose. As we noted in the introduction, there are several languages where there is no evidence for means of relativization other than correlatives.

More relevant to our concerns, the indirect-question theory again predicts that the definite reading is basic to WH-correlatives. We see this if we think about examples like 12 again: a source construction like 'You know which wall is next to the road' could conceivably be reanalyzed as 'You know the wall which is next to the road', which is the definite reading. Again, the universal reading would be expected to require additional machinery.

Another variant of the reanalysis theory of correlatives has been proposed by Hendery (2012:179ff.), based on the analysis of Georgian in Harris 1994. While Old Georgian had only 'European-style' postnominal externally headed relative clauses with interrogative pronouns, Modern Georgian developed a certain type of prenominal relative clause that Harris terms 'pre-nominal-gapped relative' (17), which, indeed, resembles a correlative construction and has been interpreted as such by some typologists (Cinque 2005:77, n. 49, Hendery 2012:180).

(17) Georgian (South Caucasian)

[Durmišxan-s Alget-ze rom c'iskvili eč'ira ], is c'iskvili ... Durmišxan-DAT Alget-on COMP mill he.have.it that mill

'the mill which Durmishxan had on Alget ...'

(Georgian; Harris 1994:134 apud Hendery 2012:180) ${ }^{21}$

Harris shows that this development has probably occurred due to the combination of two factors: (i) a general change from head-initial to head-final word order (which allowed the relative clause to shift to prenominal position) and (ii) the reanalysis of the

\footnotetext{
${ }^{20}$ The rhetorical-question theory has been partially revived in Hackstein 2004 for some interrogative-based complementizers in Indo-European. Notably, Hackstein's reconstruction does not include relative pronouns. For correlatives specifically, this scenario does not predict the universal reading. Nor is it immediately clear how to achieve the anaphoric binding between the interrogative and the demonstrative: in a rhetorical question, the former is not a referential expression and cannot be picked up by a pronominal or definite description later in the discourse.

${ }^{21}$ The glossing of rom has been changed from 'that' to 'COMP' to avoid ambiguity: this marker is a complementizer, not a demonstrative.
} 
external head as internal to the relative clause, which was made possible by the frequency of 'regressive case attraction' (attractio inversa): the head noun could optionally take the case of $\mathrm{NP}_{\text {rel }}$. If the construction is assumed to be a correlative- a conclusion Harris herself does not make - an additional, third step is required: the reanalysis of the relative clause as left-adjoined to the main clause rather than to $\mathrm{NP}_{\text {mat }} \cdot{ }^{22}$

While this scenario is plausible for Georgian, when applied more widely it faces the same issues as the extraposition scenario: it presupposes the prior existence of interrogative-based externally headed relative clauses and the possibility of attractio inversa. Neither phenomenon seems crosslinguistically frequent, and, as noted above, several languages with correlatives lack a productive finite pre- or postnominal interrogativebased strategy.

3.3. Summary. Let us sum up the results so far. On the formal side, the standard theory for DEM-based correlatives is unproblematic, whereas the two competing theories for wH-based correlatives both face problems: the indefinite theory because it assumes that the indefinite reading of WH-words was available in unembedded declaratives, and the interrogative theory because it does not yield correlative structures in a straightforward way. Both objections may be surmountable, but they must be addressed.

On the semantic side, the standard theory for DEM-based correlatives yields the correct prediction that their semantics should be maximalizing and, in particular, definite, because $\mathrm{NP}_{\text {rel }}$ originates as a definite description. The two competing theories about WH-based correlatives also predict maximalizing semantics and again of the definite kind. That is, in every scenario, correlatives start out as definites, which may take on generic/universal uses. As such, these theories have problems with languages where correlatives have ONLY the universal use. But such languages exist; for example, Arsenijević (2009) shows that correlatives in Serbo-Croatian, as exemplified by 18, can only have a universal interpretation.

(18) Serbo-Croatian (Slavic > Indo-European)

[Ko je ustao ], taj (onda) neka i izađe
REL.ANIM.NOM AUX raised that.one then let and go.out
'Let anyone who stood up (also) go out.'
(Arsenijević 2009:140)

None of the diachronic theories we have seen so far predicts the existence of such correlatives. Rather, it seems that there must be a pathway to correlatives that directly involves a quantificational structure.

4. An alternative scenario. The data from languages such as Serbo-Croatian, where correlatives have only a universal reading, clearly challenge not only the diachronic accounts that we just saw, but also synchronic accounts like that of Dayal (1995), which takes the definite reading to be primary and derives the universal reading through some sort of genericity or distributivity over cases. And in this respect, the analyses in Brasoveanu 2008 and Grosu \& Landman 1998 are no different, since they also assume that the definite reading is primary. ${ }^{23}$ It would be purely ad hoc to assume that languages

\footnotetext{
${ }^{22}$ Note again that the identification of this construction as a correlative is done only by typologists, not by most specialists on Georgian itself, including Harris. Indeed, the Georgian construction does not conform to our definition in 6 in that it has no overt marking on $\mathrm{NP}_{\text {rel }}$ (rom is a clause-level complementizer); this NP can even be absent altogether. Thus, even if it is a correlative, it is a very special case that may require a different grammaticalization scenario. See further discussion in the online supplement.

${ }^{23}$ By contrast, the analysis of Bittner (2001) is different because it posits a semantics that is ambiguous between a correlative and a conditional interpretation, but it does not derive the obligatory anaphoric connection in conditional structures.
} 
like Serbo-Croatian can only use correlatives under (covert) distributive or habitual operators. Also, we will see in $\$ 5.3$ that there are languages that have both $\mathrm{WH}^{-}$ correlatives and DEM-correlatives and use the first ones in generalizing RCs and the latter ones in definite RCs. If we take the definite meaning to be basic across the board for correlatives, we will end up having to stipulate that the wH-based correlatives occur only in the presence of operators that turn them into universals. ${ }^{24}$ This is obviously unattractive. Instead we should look for an analysis that makes such correlatives inherently universal. Moreover, this component should be tied to the makeup of WH-correlatives specifically, since the universal meaning is never, as we show in $\S 5$, basic in DEM-correlatives. One very natural candidate arises if we take Andrews's conditional paraphrase in 10 at face value.

Throughout this section, we represent the different readings of correlative structures as DISCOURSE REPRESENTATION STRUCTURES (DRSs), but avoid as many technicalities as we can. A DRS has two parts, a UNIVERSE consisting of new discourse referents introduced in that DRS, and a set of CONDITIONS on those discourse referents. For example, the sentence $A$ dog barks gets the DRS in 19.

(19)

\begin{tabular}{|c|}
\hline$x$ \\
\hline $\operatorname{dog}(x)$ \\
$\operatorname{barks}(x)$ \\
\hline
\end{tabular}

If the discourse continues with It is angry, we get 20 .

(20)

\begin{tabular}{|c|}
\hline$y$ \\
\hline$y=?$ \\
$\operatorname{angry}(y)$ \\
\hline
\end{tabular}

$y=$ ? represents the unresolved anaphoric expression it. Upon resolution of the anaphor we can represent the two-sentence discourse as 21 .

(21)

\begin{tabular}{|c|}
\hline$x y$ \\
\hline $\operatorname{dog}(x)$ \\
$\operatorname{barks}(x)$ \\
$y=x$ \\
$\operatorname{angry}(y)$ \\
\hline
\end{tabular}

Although we believe it is important that DRSs have a model-theoretic interpretation, ${ }^{25}$ we stay at the representational level here.

Our representations use one connective of the DISCOURSE REPRESENTATION THEORY (DRT) language, $\Rightarrow$. The basic meaning of a condition like $K \Rightarrow K^{\prime}$ (where $K$ and $K^{\prime}$ are DRSs) is that any assignment satisfying $K$ can be extended to an assignment satisfying $K^{\prime}$. So the sentence If a dog barks, it is angry gets the DRS in 22 after anaphora resolution.

\footnotetext{
${ }^{24}$ The opposite problem would occur if we took all correlatives to be underlyingly universal, but no one seems to have defended such a position.

${ }^{25}$ Kamp (1981) has already given an embedding of DRSs (with resolved anaphora) in first-order logic. Muskens (1996) showed that lambda terms over DRSs can be embedded in type theory, and Haug (2013) extended this treatment to DRSs with unresolved anaphora. The representational level that we use here is therefore entirely dispensable, but much more perspicuous than the underlying lambda terms.
} 
(22)

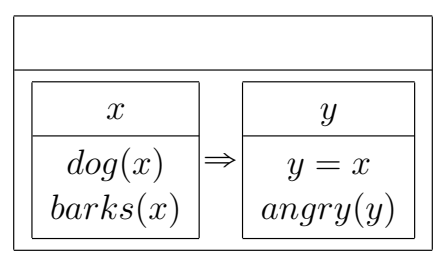

This says that any assignment that has some value for $x$ that is a barking dog can be extended to an assignment that also has a value for $y$ which is identical to that of $x$ and is angry. In other words: every barking dog is angry.

Precisely this structure can be used to formalize Andrews's intuition in 10. We adopt the following conventions: $x$ is the discourse referent introduced by $\mathrm{NP}_{\text {rel }}, P$ is the predicate of $\mathrm{S}_{\text {rel }}, y$ is the discourse referent introduced by $\mathrm{NP}_{\text {mat }}$, and $Q$ is the predicate of $\mathrm{S}_{\text {mat }}{ }^{26}$ We then get 23 .

(23)

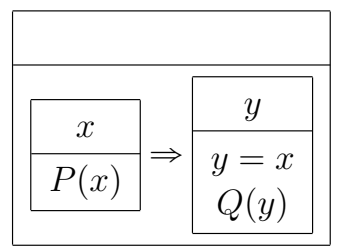

Given the interpretation of $\Rightarrow$ offered above, and the identification of $x$ and $y$, we get precisely the meaning Andrews hinted at: every $x$ that $P \mathrm{~s}, Q \mathrm{~s}$. So for 3 we get 'Mari invited every person she loves to the party'.

The typological and historical data that are available do not make it possible to generalize about the precise meaning (strict universal quantification or something weaker like genericity) involved in correlative structures and whether it is the same across languages. Fortunately, it does not matter for our purposes. What is important is that we have an explicitly quantificational structure, that is, something very different from the standard, intersection-based analyses of relativization. We continue to symbolize this quantification through $\Rightarrow$, bearing in mind that the precise interpretation might not be the original DRT one.

Intuitively, an analysis like 23 is very natural for the numerous languages where there is an overt connection between conditionals and correlatives, as in Old Tamil, where the verb of the correlative must have a special conditional form (Thomas Lehmann, p.c.), or Tibetan, where correlatives are marked with a morpheme otherwise meaning 'if', although they can have a definite meaning (Cable 2009).

(24) Tibetan (Bodic > Sino-Tibetan)

[Deb cogtse ga'di-'i 'og la yod na] sgam yang de-'i 'og la book table REL-GEN under DAT be if box also that-GEN under DAT yod red be AUX

'The box is under the table the book is under.'

(Cable 2009:205)

However, the analysis in 23 also raises a number of questions. First, how does a WHword get the semantics of an indefinite that can take on quantificational force in a conditional(-like) structure? Second, how does the conditional(-like) structure arise in

\footnotetext{
${ }^{26}$ Obviously both $\mathrm{S}_{\text {rel }}$ and $\mathrm{S}_{\text {mat }}$ can introduce other discourse referents besides those of $\mathrm{NP}_{\text {rel }}$ and $\mathrm{NP}_{\text {mat }}$, but since those are irrelevant for the correlative structure, we suppress them here and consequently also represent $P$ and $Q$ as one-place predicates.
} 
languages where there is no overt conditional morphology? Third, how does the мAтсHING CRITERION, the requirement that $x$ recurs in the consequent of 23, arise in a conditional structure? Finally, how can correlatives that arise out of conditionals take on a definite meaning, as they clearly do in many languages?

We address the first three questions in $\S \S 4.1-4.3$. We then show in $\S 4.4$ how we can put these pieces together to yield a scenario for how wH-based correlatives arise with a universal reading, explaining why the universal reading is primary with these structures. In $\S 4.5$ we then show how the definite reading can arise through further semantic evolution. Finally, in $\S 4.6$, we discuss why wH-indefinites in paratactic conditionals are particularly prone to grammaticalize into correlative structures.

4.1. IngREDIENT 1: WH-INDEFInItes. How do WH-relativizers come to take the meaning of an indefinite, as an analysis along the lines of 23 clearly implies? In some languages (Basque and Old Hungarian; see §5.3), the answer is obvious: the wH-word that is used in correlatives is not an interrogative pronoun, but an indefinite pronoun that is diachronically related to an interrogative pronoun, ${ }^{27}$ as for example in Basque or Old Hungarian, where the relevant words are formed from the interrogative pronoun by the prefixation of a particle and are used as indefinites outside of correlative structures as well (for example, in free-choice contexts). As indefinites, we expect that these pronouns will take on universal quantificational force in the scope of a conditional.

However, such languages are in the minority. In most languages, the wH-word that is used in correlatives is not an indefinite derived from an interrogative, but rather the bare interrogative itself. ${ }^{28}$ This happens in all of the Indo-European languages that have WHbased correlatives (Slavic, Latin, Anatolian, and certain Indo-Iranian languages such as Kalasha, Ossetic, and Shina), Dravidian, East Caucasian, and Turkic. Our proposal is that these relativizers are originally what we call 'Hamblin indefinites', that is, bare interrogatives used as indefinites. This is a usage that is well known typologically (Haspelmath 1997:§7.3). It is found, for example, in German; see 25. Gärtner (2009) calls this pattern 'robust' ambiguity between interrogatives and indefinites, and labels it as $[\mathrm{i}=\mathrm{i}]$ (i.e. interrogative $=$ indefinite).

(25) German (Germanic > Indo-European)

$\mathrm{Da}$ hat wer angerufen.

then have:PRS.3SG WH.NOM call:PTCP

'Then someone called.'

However, German is typologically unusual in allowing wH-interrogatives as indefinites in declarative clauses like 25. More typically, according to Haspelmath, wH-interrogatives are restricted to occur in a variety of semantic embeddings, including conditional clauses, questions, nonspecific free relative clauses, irrealis subordinate clauses, negated clauses, imperatives, and futures. This is what Gärtner (2009) calls a 'nonrobust' ambiguity between interrogatives and indefinites, labeled by him $[\% \mathrm{i}=\mathrm{i}]$.

What do these semantic environments have in common? One possible answer, following Yanovich (2005), is that they involve reference to alternatives. Yanovich's analysis treats Russian bare interrogatives as Hamblin sets, just like Japanese bare indefinite roots in the analysis of Kratzer and Shimoyama (2002). This means that the Russian clause in 26 gets the semantics in 27.

\footnotetext{
${ }^{27}$ Crosslinguistically this is an extremely common pattern that can arise in various ways, as shown in Haspelmath 1997:Ch. 6.

${ }^{28}$ Such languages may also have other indefinites that are derived from but not identical to the interrogative and that are not used in correlatives, for example, Latin quispiam 'someone'.
} 
(26) Russian (Slavic > Indo-European)

(...) kto prišël

who:NOM come:PFV.PST

(27) $\{$ ' $a$ came', ' $b$ came', 'c came', $\ldots\}$

The idea is that such alternative-denoting meanings must be bound by a higher operator. Example 26 would be infelicitous in an unembedded context because its meaning in 27 does not have an appropriate type for a declarative sentence, as it is a nonsingleton set of propositions. This straightforwardly explains the connection with the standard use of wH-words to introduce questions since - following Karttunen (1977) — questions are usually taken to denote precisely sets of propositions. In other words, taken on its own, 26 is a question. But in the course of semantic composition it can be bound by other operators, such as a conditional operator, yielding a quantificational structure 'for all $x$, if $x$ arrives, then ...' '.

Our proposal does not hinge on that specific approach to wH-indefinites. As Haspelmath (1997) and Yanovich (2005) observe, there is crosslinguistic variation in the class of licensers of WH-indefinites, and there should be some account of this. But for our purposes, the crucial observation is that conditional clauses are one of the environments that CONSISTENTLY allow WH-indefinites in languages that do have them (see Haspelmath 1997:\$7.3 and Haug 2016). If wH-correlatives arise from conditional structures, we therefore expect to see a universal reading. And this explains, we think, the remnants of conditional morphosyntax that we observe in languages such as Udihe, Old Tamil, Basque, and Old Turkic (see the online supplement for the data). All that is needed to turn such a conditional structure into a correlative is the obligatory anaphoric connection between the two clauses. We deal with this in $\S 4.3$. But what about the languages where there is no evidence for such conditional morphosyntax?

4.2. INGREDIENT 2: PARATACTIC CONDITIONALS. We have postulated that universal readings of WH-correlatives originate from a structure that is semantically conditional, as in 23. How does this semantics arise in structures that look paratactic, that is, where there is NO overt marking of the relationship between the two clauses except for the wH-word that is ex hypothesi an original indefinite?

We suggest that these are PARATACTIC conditionals (Haiman 1983) of the kind found with 'left-subordinating and' in English (Culicover \& Jackendoff 1997).

(28) You drink one more beer and I leave. $\rightarrow$ If you drink one more beer, I leave. Many languages even allow ASYNDETIC conditionals ('You break it, you own it'). Given that there is no overt marking in this structure, it is hard to get typological information on its availability and whether it is related to the availability of asyndetic coordination more generally. However, since WH-correlatives in Indo-European consistently do not contain remnants of conditional morphosyntax (see the online supplement), it is relevant to note that we find asyndetic conditionals in the earliest stages of most branches of Indo-European, and we should therefore reconstruct them for Proto-Indo-European (Delbrück 1900:420). An example from Old Swedish is given in 29 (Wessén 1965:232). ${ }^{29}$

\footnotetext{
${ }^{29}$ Among the ancient Indo-European languages, asyndetic conditionals are also found in (at least) Hittite (Huggard 2015:128), possibly Vedic (Delbrück 1900:420), Greek (Hermann 1850), Latin (Hermann 1850), and Old Russian (Birnbaum 1974:255).
} 
(29) Old Swedish (Germanic > Indo-European)

Bondä son vil sär kono bydiä. han farmer:GEN son:NOM want:PRS.3SG REFL woman:OBL propose:INF he:NOM skal hin skyldästä at hittä.

shall:PRS.3sG the nearest.kin:OBL to find:INF

'(If) a farmer's son wants to propose to a woman, (then) he shall go to her next of kin.' (Äldre Västgötalagen, 13th century)

Crucially, even in languages where unembedded declaratives do not admit Hamblin indefinites, paratactic conditionals of this kind can license a Hamblin indefinite.

(30) Russian (Slavic > Indo-European)

[WH]

Uvidišs
see:PFV:FUT.2sG who:ACC
dver' run.IMP[SG] here and hit.IMP[SG] in
door:SG.ACC two time:SG.GEN

'If you see someone, run here and hit the door two times.' (lit. 'You see whom ...')

(Russian; https://www.litmir.me/br/?b=172594\&p=63, accessed June 10, 2020)

(31) Latin (Italic > Indo-European)

negat quis, nego

deny:PRs.3sG who:NOM deny:PRs.1sG

'If someone denies (something), I deny it.'

(Terence; Eunuchus 252)

(32) Udmurt (Finno-Ugric > Uralic)

Kịtin kin viś-iś, kuradź-iś jake šuge.l'eke šed'-em

where who be.ill-PTCP.PRS suffer-PTCP.PRS or in.trouble get.in-PTCP.PRF

vań- $\mathrm{uj}=\mathrm{a}, \quad$ nunal=a kemd-e, biźi-sa vu-o

EXST night $=\mathrm{Q}$ day $=\mathrm{Q}$ happen-PRS.3sg run-CVB come-PRS.3PL

ńi val emč́i-zi dor-ị.

already PST doctor-3PL near-ILL

'If there's anyone anywhere ill, suffering, or in trouble, (then) at day or at night, doctors come running there.' (lit. 'Who gets in trouble where ... ')

(Udmurt corpus $;^{30}$ Idnakar, 2012.03.13)

In other words, although there is no evidence for syntactic subordination here, ${ }^{31}$ the semantics clearly involves a conditional operator, and this is enough to license a WH-indefinite in languages that have them.

It is worth pointing out that paratactic conditionals require subsentential (sub-CP) coordination. The conditional reading disappears if we conjoin CPs, as shown in 33. ${ }^{32}$

(33) You know of course that you drink one more beer and that I leave.

(no conditional reading)

This shows that the two conjuncts in a paratactic conditional do form a syntactic unit and are not simply discourse-coordinated.

\footnotetext{
${ }^{30} \mathrm{http} / / /$ web-corpora.net/UdmurtCorpus/search/, accessed June 10, 2020.

${ }^{31}$ This does not mean that there is no conditional marking at all in such sentences; prosody could play a role, for example. To our knowledge there is no good typological study of asyndetic (or paratactic) conditionals.

32 As pointed out to us by Rob Truswell, this is part of a larger pattern where conjoining 'larger-thannecessary' constituents forces symmetrical readings of coordinate structures. For example, asymmetric, narrative interpretations can be blocked by coordination of S rather than VP (Schmerling 1975) or CP rather than IP (Bjorkman 2013).
} 
The most elaborate semantic account of paratactic conditionals is by Keshet (2013). His suggestion (developing an idea from an anonymous reviewer cited in Culicover \& Jackendoff 1997) is that the conditional meaning arises from a modal operator whose restriction is the first conjunct of the paratactic conditional. This allows us to maintain that coordination has its ordinary meaning in sentences like 28-31. The conditional meaning arises from the modal operator that gives rise to a tripartite structure (Partee 1991).

According to Keshet (2013:222), the modal in such constructions can be either a future operator or a generic operator. In both cases, the first clause in the coordination serves as the restrictor of the modal. For example, we may paraphrase 28 with a future operator as 'In a future situation where you drink one more beer, I leave'. Example 31 can be paraphrased with a generic operator as 'Generally, in situations where someone denies something, I deny it'. For our purposes, the detailed formalization of the modals in question is not important, and we simply continue to symbolize the relevant operator as $\Rightarrow$. We can then symbolize the meaning of 31 as 34 , similar to 23 .

(34)

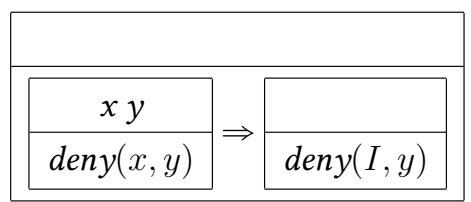

But how does 31 give rise to these meanings? The crucial semantic job is done by the covert modal operator, but what licenses the presence of this operator? And how is the semantic material divided among the restrictor and the scope of the modal? Keshet (2013: 225-32) argues that the paratactic conditional interpretation arises precisely when the main focus falls on the second clause of a conjunction, while the first clause is topical. The distribution topic-restrictor, comment-scope is as usual in modal constructions, including generic ones. Compare 35-36 from Milsark 1974.

(35) $[\text { Hurricanes }]_{\mathrm{F}}$ arise in this part of the Pacific.

(36) Hurricanes arise [in this part of the Pacific $]_{F}$.

Example 35 is interpreted as a statement about a part of the Pacific, and says that in general, there arise hurricanes in that area. Example 36, by contrast, is interpreted as a statement about hurricanes, and it says that in general, they arise in this part of the $\mathrm{Pa}$ cific. We can represent these meanings as follows in our DRT language.

(37)

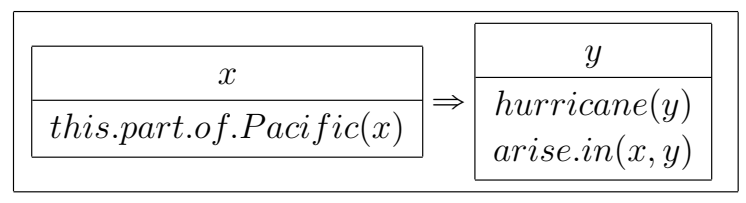

(38)

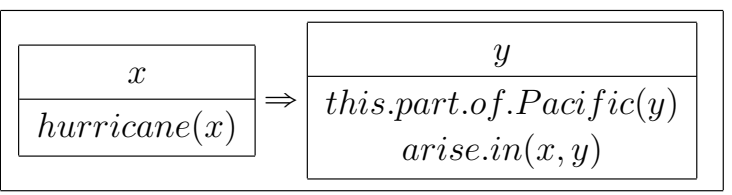

Cases like 28-31 can be assigned similar meanings, which we can generalize as a pure conditional meaning, represented in 39.

(39)

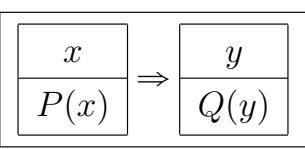


The origin of wH-correlatives in conditionals can be backed up with conditional morphosyntax in some languages. Correlatives feature elements such as a complementizer 'if' in Tibetan (Cable 2009) or conditional verbal morphology in Old Tamil (Hock 2008) and Basque (Rebuschi 2009). In fact, the Basque evidence points directly to a paratactic conditional, because the two clauses in conditional-based correlatives may be connected with eta 'and' (see the online supplement). However, many languages allow asyndetic coordination of paratactic conditionals (e.g. 30 and 31), and we often find no overt trace of a coordination. Still, the topic-comment articulation of correlatives and their tendency to left dislocation fits well with an origin in paratactic conditionals. Particularly interesting in this respect is the contrast between Dravidian and Indo-Aryan correlatives. IndoAryan correlatives are thought to be DEM-based and have developed a postposed use, ${ }^{33}$ while Dravidian correlatives are wH-based and must be preposed. As noted by Hock (2008:172), this speaks against borrowing. We add that it also fits well with a conditional structure as the origin for the Dravidian but not the Indo-Aryan structure.

4.3. INGREDIENT 3: THE ANAPHORIC CONNECTION. What is missing in 39, compared to the source meaning we postulated in 23 , is any kind of anaphoric connection between individual-denoting terms in the clauses: we have a pure conditional structure. All that is needed for a correlative to arise is the matching criterion, the obligatory anaphoric connection between the two clauses, to which we now turn. As has often been observed, this is what sets correlative structures apart from conditionals. Unfortunately, we know of no language where we can observe this development in the texts. However, we argue that the development is not unexpected, but results from natural tendencies in linguistic change.

One argument comes from languages that attest an interesting intermediate step, where there must be an anaphoric relation between the correlative clause and the matrix, but the anaphor is not necessarily fully coreferent.

(40) Ossetic (Iranian > Indo-European)

[adsjmag $\chi^{\mathrm{w} ə z ̌ d з r ~ s ə ~ v z ̌ a g-ə l ~ z u r-a ~], ~ w ə-s ə ~}$

person better REL language-SUPER speak-SBJV.3SG that-DET

ad3məðat:-3j u

ethnicity-ABL be.Prs.3sG

'A person is from the nation whose language s/he speaks better.' (lit. 'Which language a person speaks better, from that ${ }^{34}$ nation $\mathrm{s} / \mathrm{he}$ is.')

(proverb, Ossetic National Corpus)

(41) Hittite $^{35}$ (Anatolian > Indo-European) [PÍŠ ga-pár-ta=na=kán ku-in $A$-NA DÙ EME ši-pa-an-ta-aš ]
animal:ACC=CONJ=PTCL REL:ACC to made tongue sacrifice:PST.3sG
nu UZUNÍG.GUG UZUZAG.UDU ha-ap-pí-ni-it za-nu-zi CONJ intestines:ACC shoulder:ACC flame:INS burn:PRs.3sG

'He roasts the intestines and the shoulders of the animal ${ }^{36}$ which he had sacrificed to the artificial tongue.' (lit. 'What animal he had sacrificed to the artificial tongue, he roasts intestines and shoulder with the flame.')

(Probert 2006:63)

\footnotetext{
${ }^{33}$ As was mentioned above, Srivastav (1991) argues that such cases should be treated as right-dislocated, externally headed constructions, but since the relativizer is the same, we assume the construction is at least diachronically related to the correlative construction.

${ }^{34}$ The determiner wasa 'that' is distinct from the genitive form of the demonstrative, which is waj 'of that'.

${ }^{35}$ In contradiction to the Leipzig rules, and according to tradition and the source, the hyphens in the Hittite example correspond not to morpheme boundaries, but to the boundaries between cuneiform syllabic signs.

${ }^{36} P I ́ S \zeta$ ga-pár-t is really the name of an unknown animal rather than a generic term for animals.
} 
(42) Ashti (Dargwa > East Caucasian)
[si lusat.li-ži-w
ьaj.ka:k'-ul=il
], te: ummat-la
REL language-SUPER-M[ESS] M:speak.IPFV-PRS[3]=IQ that nation-GEN w-i $\chi^{\mathrm{w}}-\mathrm{a} \quad$ har.il insan
M-be.IPFV-HAB. 3 every person

'Which language a person speaks, from that nation s/he is.'

(Oleg Belyaev's field notes, 2014)

$[\mathrm{WH}]$

Given that such intermediate stages are attested, it is plausible to assume a gradual obligatorification of the anaphoric connection. The mechanism is not mysterious. Both conditionals and correlatives proper have affinities with topic-comment structures, and as we saw this articulation is fundamental to the source construction we assume. Furthermore, it is well known that there must be a certain connection between topic and comment for the utterance to be felicitous. Obligatory anaphora is one way of assuring such a connection. We can see this mechanism at work in another relative construction, English such that relatives. These often contain a pronoun referring back to the head of the relative clause, as in 43.

(43) Every $_{i}$ polygon such that it $_{i}$ has exactly three sides is a triangle.

It has even been argued (Higginbotham 1984) that such that relatives MUST contain a pronoun referring back to the head, based on the claim that NPs like 44 are ungrammatical (as opposed to, say, semantically anomalous).

(44) *?every book such that it rains

However, Pullum (1985) shows that there are such that relatives without an anaphoric connection to the head and, moreover, that there are several examples of this in the earliest documentation of attributive such that relatives in the Oxford English Dictionary, for example, 45 from 1876.

(45) statesmen, who had assumed an attitude such that they could not very well avoid being either insincere or ungracious

Here too there is an indirect anaphoric connection in that they refers to the holders of the attitude, which is the head of the such that relative. It seems plausible, then, to assume a gradual evolution from no referential connection between the clauses, via a partial referential connection, to obligatory full referential connection, both in such that relatives and in correlatives.

In terms of our DRT representations, we can represent an obligatory anaphoric connection between two discourse referents $x$ and $y$ with a condition $\mathcal{A}(y)=x$ (the antecedent of $y$ is $x$ ), remembering that anaphoric connections can be formed with bridging and do not entail full coreference. ${ }^{37}$ To enforce full coreference, an additional condition $x=y$ is needed. Schematically, we may then express the proposed semantic evolution as the cline in 46.

(46)

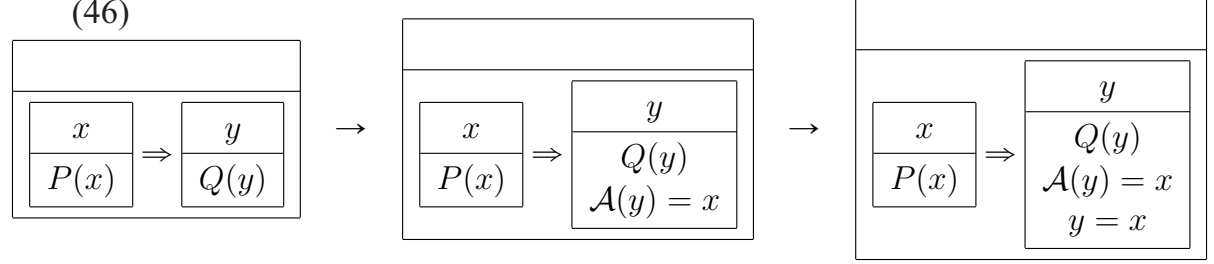

${ }^{37}$ For more detail on the treatment of bridging in correlatives within a version of DRT, so-called PARTIAL COMPOSITIONAL DRT, see Belyaev \& Haug 2014. In this article we use DRSs merely to represent different readings, but notice that Belyaev \& Haug 2014 includes model-theoretic interpretations of the anaphoric conditions. 
In this structure, then, the maximalizing semantics of correlatives is realized as a universal reading that arises from the conditional structure.

As a referee points out, conditionals already involve an anaphora-like connection between the antecedent and the consequent since the situations described in the two clauses must be related. In the analysis of Bittner (2001) this relationship is modeled as anaphora between SITUATION-TYPE variables, and the only difference between conditionals and correlatives is that the latter involve INDIVIDUAL-TYPE anaphora. But notice that Bittner's analysis by her own admission does NOT cover universal readings of correlatives (Bittner 2001:54, n. 7). Therefore we cannot model the change from conditionals to correlatives as simply a change in the semantic type of the anaphora. However, it does seem possible to model the change within a Bittner-type system as an additional requirement that the two sentences are related by TwO anaphoric connections (situation-level and individual-level). And more generally, it is worth keeping in mind that all of the relevant constructions (topic-comment, conditionals, correlatives) are integral discourse units whose cohesion improves with anaphoric connections. ${ }^{38}$

4.4. Putting the ingredients together. We have seen that three ingredients are necessary for our scenario to give rise to wH-based correlatives. Two of these are quite widespread typologically, namely paratactic conditionals and a tendency toward tighter semantic integration of topic-comment structures via obligatorification of anaphoric connections. If a language also has WH-indefinites, we expect that WH-correlatives can arise.

It is in the nature of things that we cannot actually prove that wH-based correlatives arise from paratactic conditionals by observing the evolution in historical texts. Most of the languages involved have a short documented history, and even in those that do not (mainly the Indo-European languages), correlatives are present from the earliest texts. Nevertheless, our scenario makes a number of correct predictions about wH-correlatives. First and foremost, it explains the primacy of the universal reading, as opposed to the primacy of the definite reading in DEM-correlatives. As we will see in $\S 5$, there is widespread typological support for this. Second, it has often been observed in the literature that correlatives have a topic-comment structure. Our account provides a direct explanation of that, since the structure is inherited directly from that of paratactic conditionals. Related to this are the word-order facts: correlatives are generally positioned to the left, like antecedents in paratactic conditionals. Third, since wH-correlatives on our account arise from anaphoric structures (specifically donkey anaphora in a paratactic conditional), we predict the existence of correlatives with only partial referential overlap between $\mathrm{NP}_{\text {rel }}$ and $\mathrm{NP}_{\text {mat }}$, as illustrated in $\S 4.3$. Fourth, our account explains why WH-correlatives occur in languages (such as Turkish) that otherwise lack wH-relatives, unlike accounts that derive $\mathrm{WH}$-correlatives from topicalized free relatives.

In terms of the debate we mentioned in $\$ 3.2$, as to whether wH-relatives arise from WH-interrogatives or WH-indefinites, our analysis sides with the indefinite analysis. Luján (2009) has raised an objection to this view by pointing out that there are no languages where the same pronoun is indefinite and relative but not interrogative: that is, the semantic map is INDEF-WH-RED rather than WH-INDEF- REL. However, the force of this objection disappears when we consider that indefinites and interrogatives are identical in the relevant contexts (Hamblin indefinites in conditional structures).

We therefore think that our analysis is well supported and provides an elegant account of why the universal reading is basic in WH-correlatives. Nevertheless, WH-

\footnotetext{
${ }^{38}$ See Asher \& Lascarides 2003 for a fully developed, scalar notion of discourse coherence emphasizing the role of anaphoric connections.
} 
correlatives can ALSo have a definite reading (though never ONLY a definite reading), as we will see in $\S 5$. We must now show how that reading can arise from the universal one.

4.5. The Definite READING. The main challenge is to explain how this reading can arise from an essentially quantificational structure. We propose that there are two relevant contexts for reanalysis: predicates that are uniquely satisfied, and plural predicates.

Consider unique predicates first. One example is 47 , which can be construed as quantifying over a singleton set.

(47) Latin (Italic > Indo-European)

[quam earum in iis locis optimam

$[\mathrm{WH}]$

REL.ACC.SG them:GEN.PL in these:ABL.PL places:ABL.PL best:ACC.SG

dicent esse ], eam maxime serito

say:FUT.3PL be:INF that:ACC.SG in.particular sow:IMP.3sG

'(the crop) which they say is best in these places, sow that one in particular'

(Cato, de Agricultura 6.1)

The meaning of 47 at a stage where only the universal reading is available would be 'If they say that some crop is best in these places, sow that one in particular'. This is very close in meaning to the definite reading 'The crop that they say is best in these places, sow that one'. In fact, the two are truth-conditionally equivalent if there is one (existence) and only one (uniqueness) $x$ such that $x$ is a crop that they say is best in these places. Existence is in fact given by the quantificational structure: it is a common assumption that quantification presupposes that the domain of quantification is nonempty. So uniqueness is the critical point. In this case, the predicate 'they say that $x$ is the best crop here' does not entail uniqueness (unlike ' $x$ is the best crop here'), but to the extent that we infer uniqueness pragmatically, reanalysis as a definite is possible.

Although this reanalysis must have happened before the historical record, there are numerous examples - in early Latin texts, for example - of correlatives with a definitelike reading which have predicates that entail uniqueness. See also 48, where the context makes clear that the man in question had three wives so that there is a unique middle wife. Similar examples where the correlative clause is uniquely satisfied are common in other languages, as in 49.

(48) Latin (Italic > Indo-European)

[medioxumam quam duxit uxorem ], ex ea

middle:ACC.SG REL.ACC.SG led:PFV.PST.3sG wife:ACC.SG from her:ABL

nata est

born:NOM.SG is:PRS.3sG

'She was born from the middle woman whom he had for a wife.'

(Plautus, Cistellaria 2.3.67)

(49) Hungarian (Finno-Ugric > Uralic)

[Vala-kit megapolandoc ] o az fogiatoc optèt

VALA-REL.ANIM:ACC PRT:kiss:FUT.1SG he that detain:IMP.2SG he:ACC

'The one I am going to kiss, he will be the one; detain him.'

(Bende-Farkas 2015:239)

Such examples, then, offer a natural environment for the definite reading to arise, as shown in $50 .{ }^{39}$

\footnotetext{
${ }^{39}$ In the discussion and in the DRSs we stick to the straightforward case where $\mathrm{NP}_{\text {rel }}$ and $\mathrm{NP}_{\text {mat }}$ are coreferent, but the same point is true if they stand in a (functional) bridging relationship, that is, if we are at the middle stage of the cline in 46.
} 
(50)

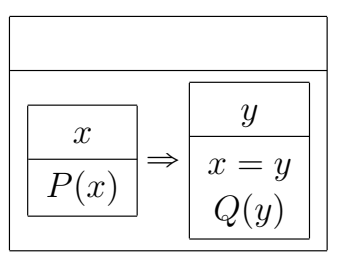

\begin{tabular}{|c|}
\hline$x y$ \\
\hline$P(x)$ \\
$x=y$ \\
$Q(y)$ \\
\hline
\end{tabular}

To illustrate the point in an informal way using our example 3: if we know there is only one person who Mari loves, then saying that if someone is that person then $\mathrm{s} / \mathrm{he}$ was invited is equivalent to saying that someone is that person and was, indeed, invited. In other words, the universal and the definite readings will amount to the same since we are quantifying over a singleton set. However, if there is more than one such person, then the statement 'If Mari loves someone, then she invited him/her' is stronger than 'There is someone that Mari loves and she invited him/her', because only the former entails that all people loved by Mari were invited.

The second context that allows reanalysis is plurals. The reason is that if $\mathrm{NP}_{\text {rel }}$ is plural so that the discourse referent $x$ ranges over pluralities, then universally quantifying over pluralities who Mari loves will yield similar truth conditions as a predication of the maximal group of individuals who Mari loves. Informally, the statement 'If $x$ is a group containing persons Mari loves, then the members of that group have been invited' is equivalent to the statement that 'There is a unique group of all persons Mari loves and all members of this group have been invited', because there will be a unique group that is the sum of all the groups $x$ that the first statement quantifies over. In other words, in correlatives with a plural $\mathrm{NP}_{\text {rel }}$, the universal and the definite readings will amount to the same, mirroring the intuition that a definite plural is similar to a universal. Therefore the conditions for the reanalysis in 50 are fulfilled.

Although the truth conditions of the two DRSs in 50 are the same in unique and plural contexts, the anaphoric accessibility pattern is different: the right-hand side, but not the left-hand side, introduces a discourse referent that is globally available for anaphoric reference in the subsequent discourse. In this sense, the indefinite-marked $\mathrm{NP}_{\text {rel }}$ increases its scope. This change is in accordance with what we know about the evolution of indefinites: they tend to start out specialized for various embedded contexts and then generalize to more and more contexts - that is, they get ever more scope possibilities (Haspelmath 1997:§6.4).

It is rather typical for semantic reanalysis to be triggered by restricted contextual environments that allow both the old and the new interpretation, which are called CRITICAL CONTEXTS in Diewald 2002. Uniquely satisfiable predicates and plural predicates offer exactly such environments for correlatives. Contexts such as 48 may even be classified as PRECARIOUS CONTEXTS in the sense of Eckardt $(2006,2011)$, as while they are formally compatible with a quantificational interpretation, the unique reading is pragmatically more plausible due to the obvious uniqueness of the referent.

So we have a plausible scenario for how the definite reading can arise from the universal one. In this way we can make sense of why there are languages where correlatives are marked with conditional morphology even when they have a definite reading, as can happen in Tibetan (24). A final point is worth noting: as we noted in n. 6 this scenario is independent of the full coreference requirement. That is, the proposed evolution could happen at either of the two last stages in 46. This is consistent with the typological data: there are languages such as Ossetic with wH-correlatives where full coreference is not needed, but the definite reading is already available. 
4.6. Why BARE WH-INDEFINITES? We have seen that there is a plausible pathway from paratactic conditionals with Hamblin indefinites to correlative structures with an originally universal meaning that can be expanded to include the definite meaning. This evolution cannot be followed in the texts - indeed, no emerging correlatives are attested in the historical record - but as we will see it explains the typological pattern as well as a number of other properties of these correlative constructions, and as such it has considerable explanatory force.

It is easy to see why paratactic conditionals are a good candidate for grammaticalization. They are cohesive syntactic units (as we saw in $\S 4.2$, they involve sub-CP coordination), and they are information-structural units, with one conjunct serving as the topic and the second conjunct as the comment.

But what makes bare wH-indefinites good candidates to develop into relativizers in the first place? Given that it is relatively common for correlatives to involve wH-words (in languages that have correlatives in the first place), one might ask what it is about these words that invites grammaticalization. Recall that the standard scenario proposed in the literature for $\mathrm{WH}$-based relative pronouns, as discussed in $\$ 3.2$, does not lead to correlatives. Nothing of what we said in $\S 4.1$ hinges on the particular semantic properties of wH-indefinites: any indefinite that can take narrow scope under a conditional would in principle do. Nevertheless we do not, to our knowledge, find correlatives based on ordinary indefinites where the determiner is an indefinite article like English $a$ or just null. ${ }^{40}$

We believe there are many reasons for this. At a fundamental level, the source construction is paratactic, whereas in the resulting correlative structure, $\mathrm{S}_{\text {rel }}$ is subordinate to $S_{\text {mat }}$, for example by being adjoined to $S_{\text {rel }}$ as in 7 . In fact, because conditionals are so close to the universal reading of correlatives, this plus the obligatory matching criterion is the only change needed to turn a paratactic conditional into a correlative. And the fact that Hamblin indefinites are licensed by an operator that is present only in the whole $\mathrm{S}_{\text {rel }}-\mathrm{S}_{\text {mat }}$ construction may make it more suitable as a marker of this subordination. By contrast, an ordinary indefinite would be interpretable inside its own clause without a particular connection to the wider syntactic context.

Moreover, the presence of $\mathrm{NP}_{\text {rel }}$ is the only thing that marks subordination in correlative structures. We conjecture that a null determiner or an ordinary indefinite article in $\mathrm{NP}_{\text {rel }}$ is simply not able to carry this syntactic weight. A null determiner gives no indication of subordination, whereas an indefinite article (in languages that have them) is too general to serve as an indication of subordination. By contrast, wH-indefinitesparticularly bare Hamblin indefinites - will already serve to mark subordinate clauses in interrogative complement clauses. That is, although the definite semantics of indirect question clauses means they are not the origin of correlative clauses (as argued in §3.2), the existence of such clauses marked by WH-words may well have supported the grammaticalization of correlative structures with similarly introduced clauses, and may even have supported the later development of the definite meaning.

Another, complementary reason might be that bare Hamblin indefinites, unlike other indefinites, are only licensed under the scope of conditional operators, so that they can easily fill a niche for generalizing, conditional-like relative clauses, even if the language already has some other means of relativization available. In a later stage, such

\footnotetext{
${ }^{40}$ At this stage of our research, we do not want to exclude the possibility that such indefinites can grammaticalize as correlative markers, but so far we have found no examples.
} 
generalizing relative clauses can be extended to ordinary definite relative clauses. Finally, it is worth noting that Hamblin indefinites are inherently polyfunctional: as was shown by Kratzer and Shimoyama (2002), they have a very indeterminate basic meaning (a set of alternatives), and it is the syntactic and semantic context that manipulates this meaning to give rise to a question meaning, or a universal or existential quantification, or, we argue, a correlative structure. This very indeterminacy feeds the potential for reanalysis.

5. TYPOLOGY.

5.1. ThreE PREDICTIONS. The analysis of the evolution of WH-correlatives we have established in the preceding section allows us to make three typological predictions.

First, if the proposed scenario is indeed the primary historical pathway by which wHcorrelatives are innovated, we can expect the universal reading to be primary and universally available. The definite reading, being historically only an extension of the universal reading, is expected to be secondary. Therefore, if a WH-correlative has a definite reading, it must also have a universal reading.

Conversely, if the pathway proposed by Givón (2009) is primary for DEM-correlatives, we expect the definite reading to be primary and universally available in this type, and the universal reading, if present, to be only secondary.

Therefore, two implicational universals, mirror images of each other, can be provided for two types of correlatives.

(51) a. WH-correlatives: Def $\rightarrow$ Univ

b. DEM-correlatives: Univ $\rightarrow$ Def

Of course, this does not have to be an absolute universal, because, after all, we do not and cannot rule out other pathways by which correlatives come into being, nor can we exclude the possibility that the old meaning was lost after the new meaning developed. Nevertheless, we assume that the scenario does explain the majority of cases where WH-correlatives have developed in languages that do not have full interrogative-indefinite ambiguity; therefore, the number of exceptions should be relatively low, and the fewer the exceptions, the greater the explanatory force of our theory.

Second, if wH-correlatives develop from conditional structures, we can expect to find traces of conditional morphology at least in some languages. This is not necessarily so, of course, because correlatives can well develop from fully asyndetic conditionals. However, even such conditionals can contain some morphological cues to their semantics, such as subjunctive or conditional mood. Furthermore, nothing rules out the development of correlatives from nonparatactic, fully marked conditional structures, and in this case subordinators with the meaning 'if' can easily remain part of the structure.

Third, we noted in $\S 4.6$ that $\mathrm{WH}$-correlatives are particularly likely to arise in languages with Hamblin indefinites, but without full interrogative-indefinite ambiguity. Unless interrogative-indefinite ambiguity is lost or extended at some stage in the evolution of grammar, we can expect to find the same kind of ambiguity in all languages that have this kind of correlative structure.

5.2. Methodology. In order to prove an implication $A \rightarrow B$, one should first demonstrate the existence of two possible kinds of constructions. ${ }^{41}$

\footnotetext{
${ }^{41}$ We exclude $\neg A \wedge \neg B$ for its triviality: since we are dealing with correlative constructions, they obviously need to have some interpretation; indefinite correlatives do not exist, so there are only two possibilities.
} 
(52) a. $A \wedge B$ (wH-correlatives, DEM-correlatives: +Def, +Univ)

b. $\neg A \wedge B$ (wH-correlatives: -Def, +Univ; DEM-correlatives: -Univ, +Def $)^{42}$

The existence of these constructions seems rather uncontroversial. For wH-correlatives, examples of $A \wedge B$ are Hittite (Anatolian > Indo-European) and Tibetan (Tibeto-Burman $>$ Sino-Tibetan). The type $\neg A \wedge B$, where the universal reading is the only one available, is in fact somewhat more frequent than the type that has both readings; examples are Serbo-Croatian (Slavic $>$ Indo-European) and Chinese (Sinitic $>$ Sino-Tibetan).

Obtaining the relevant data for DEM-correlatives is more complicated, as the number of languages for which such constructions are described in sufficient detail is quite limited. There are a few reliable examples of $\neg A \wedge B$, namely languages where only the definite reading is available, in particular Bambara, about which Dumestre (2003:36769) states that correlatives with the relativizer min are used in definite contexts, while in universal contexts, a different, noncorrelative internally headed construction with the relativizer $o$ is used instead. At the same time, there are, somewhat surprisingly, no clear cases of $A \wedge B$ : as is explained in the next section, in all languages with DEM-correlatives that allow universal readings, these readings are licensed only in the scope of an overt habitual or conditional operator. This strongly suggests that the universal reading is not available in episodic contexts, and thus there is no real quantificational semantics in any of the constructions in our sample.

The second component of proving an implicational universal is much more complicated: it involves demonstrating that there are No languages where $A \wedge \neg B$ is true (wH-correlatives: +Def, -Univ; DEM-correlatives: +Univ, -Def). Since one cannot enumerate all existing (much less all possible) languages, typologists typically resort to balanced samples that rule out genealogical or areal bias. However, such a sample would not be useful for our purposes, as the overwhelming majority of languages do not have correlatives. Even those that do often lack descriptions involving sufficiently detailed overviews of their semantics. In certain cases, texts or examples in grammars may be used, but such sources can never be conclusive, because one needs negative evidence in order to rule out the availability of one of the interpretations.

Therefore, the nature of our data requires the use of a convenience sample rather than a balanced sample. Our sample contains thirty-eight constructions in thirty-two languages, which is close to representing the maximum amount of information that we currently have on correlatives. Most of the languages with wH-correlatives are from Eurasia, and the majority of them are Indo-European. Hence, influence from language contact cannot be ruled out. But even if language contact is admitted for some cases, it does not necessarily render those data points invalid: when there is no direct borrowing of material or ongoing language shift, the development of new constructions rarely occurs via direct calquing; the usual contact mechanism is by triggering regular grammaticalization patterns in the borrowing language (contact-induced grammaticalization; Heine \& Kuteva 2003). Finally, it is worth mentioning that in many cases, we know that the correlative constructions in question have arisen independently, as in, for example, the case of Dravidian languages, which have wH-correlatives while the neighboring Indo-Aryan languages have (most probably) DEM-correlatives. In other cases we can clearly see that contact influence is improbable due to the differences in the distribution of the constructions.

\footnotetext{
42 This part is not strictly necessary for an implicational universal, but if such languages do not exist, the implication will essentially amount to an equivalence, which is not the desired result: our claim is that the two readings do not necessarily coexist in a given correlative.
} 
Languages with DEM-correlatives in our sample are much more diverse, but their overall number is smaller due to the lack of sufficiently adequate descriptions. Nevertheless, we argue that the data that is available is enough for a preliminary confirmation of our hypothesis, not in the least due to indirect evidence pointing to the primacy of the definite reading within particular languages.

In sum, our typological predictions were tested on a sample that contains nearly all of the information that is currently available. The makeup of our sample, detailed explanations, and justifications for assigning specific feature values can be found in the online supplement. In this section, we provide only specific results and deal with outstanding issues.

\subsection{THE READINGS OF CORRELATIVES.}

Wh-CORRELATIVES. Overall, both correlations are confirmed. In the following tetrachoric table (Table 1), we can see that there are only two potential exceptions to the implication Def $\rightarrow$ Univ for wH-correlatives.

$\begin{array}{lcc} & \text { Univ } & \neg \text { Univ } \\ \text { Def } & 8 & 2 \\ \neg \text { Def } & 16 & -\end{array}$

TABLE 1. Testing universal 1 (WH-correlatives: Def $\rightarrow$ Univ).

The two potential exceptions come from Tamil and Standard Dargwa. In both languages, the relevant WH-correlative construction exists alongside another wH-correlative construction, which has only a universal reading. As such, it would be tempting to treat them as cases where a wH-correlative requires special marking to get the definite reading, but intuitively the differences between the constructions are too large to treat them as a single construction: in Tamil, a finite verb is used in definite correlatives, as opposed to the conditional converb in universal correlatives; in Standard Dargwa, an indirect question marker, as opposed to a conditional form. Nevertheless, we believe the same logic is at work: these languages have developed a special WH-correlative to express the definite meaning. For Tamil, we can actually see that the definite construction is a later development since Old Tamil has only universal correlatives. For Standard Dargwa, it is worth pointing out that the data are uncertain since all available examples are in fact ambiguous between a universal and a definite reading; see the online supplement for more information. In other Dargwa varieties, such as Ashti Dargwa, the indirect-question construction does, in fact, have a universal interpretation; see 42 above.

In sum, we take the data to overwhelmingly confirm our generalization. In particular, it is interesting that the 'universal-only' type is in fact more frequent than the type that has both readings. Note that this result is unlikely to be due to a bias in the sample. If the sample is biased toward a family, it is Indo-European. However, among Indo-European languages, 'universal-only' correlatives are in fact a slight minority: four out of ten. This makes the result quite robust. It is difficult to explain in the standard maximalization approach, which takes both the universal and the definite readings for granted.

Dem-Correlatives. The situation with DEM-correlatives is somewhat more complicated. First of all, there are fewer of them in the sample, and the sampling is heavily biased: even though such constructions are known to exist in other linguistic areas (such as in Sanuma in South America; Borgman 1990), there is simply not enough data to draw any kind of conclusions on the interpretations of these constructions. Second, as mentioned above, many DEM-correlative languages in the sample are marked as $+/-$ for 
the universal reading. The meaning of this notation is that the universal reading is available only in the presence of an additional irrealis or habitual operator, such as in the following examples from Kita (Mande).

(53) Kita (Mande > Niger-Congo), definite

[ídi worì mín tà ] à dú $\mathrm{n}$ mà!

2ACP.POS money.DEF REL take 3 give 1SG POSTP

'Return to me the money that you've taken!'

$[\mathrm{DEM}]$

(54) Kita (Mande $>$ Niger-Congo), universal ${ }^{43}$

[ní min bòyi-da ] à b' ó tà

if REL fall-ACP.POS 3 INACP.POS DEM gather

'He gathers whatever falls down.' (lit. 'If which falls down, he gathers

that.')

(Creissels 2009, ex. 22b)

In other words, the universal reading of correlatives in these languages is in fact a generic one, due to the presence of a modal or habitual operator; no true quantification occurs in episodic, indicative contexts. This is in sharp contrast to most languages with WH-correlatives, where the universal interpretation is typically available in episodic contexts, as in 55 .

(55) Ossetic (Iranian > Indo-European)

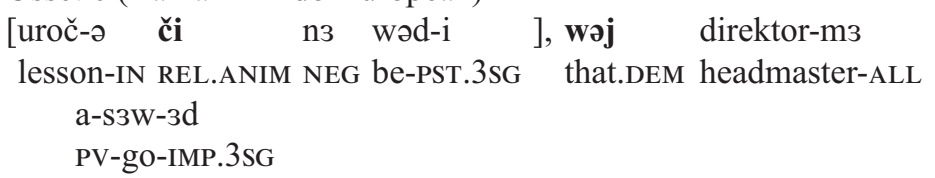

[WH]

'Let the one who/whoever was not at the lesson come to the headmaster.'

(Belyaev 2014:199)

Hence, for our purposes, languages requiring additional morphology to get the universal readings can be classified as $\langle+$ Def, - Univ $\rangle$. This leads to a tetrachoric table that suggests a stronger kind of universal than an implication (Table 2): DEM-correlatives with true universal readings are absent altogether.

$\begin{array}{lcc} & \text { Def } & \neg \text { Def } \\ \text { Univ } & 0 & 0 \\ \neg \text { Univ } & 12 & -\end{array}$

TABLE 2. Testing universal 2 (DEM-correlatives: Univ $\rightarrow$ Def).

While this result may seem surprising at first, it is to be expected if we consider the semantic difference between interrogatives (Hamblin indefinites) and demonstratives. The former denote sets and are thus inherently polyfunctional, obtaining particular interpretations in the scope of various external operators; see Kratzer \& Shimoyama 2002. This creates the potential for further semantic reanalysis. In contrast, demonstratives, third-person anaphoric pronouns, or definite descriptions do not have this ambiguity, and hence there is not much opportunity for them to obtain additional readings. This is consistent with our proposal that definite readings in wH-correlatives and universal readings in DEM-correlatives arise secondarily due to semantic reanalysis, and the differences in crosslinguistic distributions of these meanings are due to differences in the way this reanalysis proceeds in each case.

LANGUAGES WITH BOTH TYPES OF CORRELATIVES. While the majority of languages in our sample have only one type of correlative (demonstrative or interrogative-based),

\footnotetext{
${ }^{43}$ The lack of tone marking on $\min$ (unlike the previous example) follows the source.
} 
there are a few examples that are specifically interesting because they have two correlative constructions: one demonstrative, and one interrogative. These languages are: Old Czech (Slavic), Ket (Yenisean), and Udihe (Tungusic). Old Czech in particular seems to represent a perfect confirmation of our theory. In the history of this language, correlatives with both interrogative- and demonstrative-based pronouns coexisted for some time. ${ }^{44}$ Their semantic distribution is quite remarkable. As Bauer (1972:40-41) demonstrates, in Old Czech 'les [propositions relatives avec jenž, ješto] [i.e. demonstrative *yo-based relatives - $O B \& D H]$ indiquaient d'habitude le caractère d'une personne ou d'une chose connue, les [propositions relatives avec kto, čso, který] [i.e. interrogativebased relatives- $O B \& D H]$ se rattachaient à une personne ou à une chose en général'. That is, DEM-relatives in Old Czech refer to known/definite individuals, while WHrelatives are generalizing. He provides the following examples to illustrate this point.

(56) Old Czech (Slavic > Indo-European), DEM-based jehož někdy najvěrnějšieho mnieše, REL.M.SG.ACC sometimes most.loyal:M.SG.ACC consider:AOR.3PL
tomu
káza
na nátonu bradu
obrubati

that:M.SG.DAT order:AOR.3sG on log:SG.LOC beard:SG.ACC cut.off:INF

'He ordered to cut off the beard on the (wood) log to the one who was con-

sidered the most loyal.' (Bauer 1972, adapted from the Chronicle of Dalimil 59,50)

(57) Old Czech (Slavic > Indo-European), wH-based

kdo chce zbýti strasti, nerod'

REL.M.SG.NOM want:PRS.3sG stop:INF sorrow:PL.ACC not.care:IMP.2sG

prsta mezi dřvi a podvoj klásti

finger:DU.ACC between door:SG.INS and frame:SG.INS put:INF

'Whoever wants to stop sorrows should not put two fingers between a

door and its frame.' (Bauer 1972, adapted from the Chronicle of Dalimil 85,58)

According to Bauer, later in the history of Czech, interrogative-based relative clauses gradually extended their function, such that they started to be used in both contexts, and jenž 'which' and other DEM-based correlatives were displaced to their marked stylistic (archaic) variants. This perfectly corresponds to our theory.

Ket and Udihe are somewhat less conclusive due to fragmentary data on these languages, but, based on available examples, the overall distribution seems to be the same as in Old Czech: DEM-correlatives have definite readings, and WH-correlatives have universal readings.

AN OUTLIER: CORRELATIVES WITH EXTENDED INTERrogatives. We mention for completeness that there are two cases of wH-correlatives in our sample, Basque and Old Hungarian, that are not quite typical examples of our scenario in that the pronouns used are not bare interrogatives but interrogatives extended with various elements.

In Basque (Rebuschi 2009), the interrogative is extended with the element ere, whose meaning is similar to English -ever. They are accompanied by the conditional prefix bait- on the verb. Therefore, the construction is still conditional in nature, and the basic scenario that we proposed still applies to Basque. The same situation seems to have obtained in Old Hungarian, which used the indefinite prefix vala- and conditional marking (Bende-Farkas 2015). This construction has apparently been replaced by another kind of correlative in modern Hungarian (Lipták 2008).

\footnotetext{
${ }^{44}$ We are grateful to Maria Kholodilova for drawing our attention to this data, and to Anton Zimmerling for help with glossing and interpretation.
} 
These are the only two wH-correlative constructions in our sample where the relativizer is an extended interrogative. The fact that the grammars describe them as very close to conditionals suggests that they were not fully grammaticalized as correlatives. We therefore ignore them in this article.

5.4. CONDITIONAL MORPHOLOGY In CORRElatives. Since our scenario involves the development of correlatives from conditionals, we expect that at least in some languages the original constructions are not paratactic, but involve some kind of overt conditional marking. Several languages in our sample do in fact retain this marking in correlatives. These are marked by the plus sign in the 'cond.' column in the online supplement. This includes both languages where a conditional element is obligatory, such as Tibetan (58), and languages where conditional morphology is optional, such as Udihe (59).

(58) Tibetan (Bodic $>$ Sino-Tibetan)

[Khyodra-s gyag gare nyos yod na] nga-s de bsad pa yin.

[WH] you-ERG yak REL buy AUX if I-ERG that kill PRF AUX

'I killed whatever yak you bought.'/'I killed the (particular) yak you bought.'

(Cable 2009:198)

(59) Udihe (Tungusic > Altaic)

sii ono diana-isi-i,

bii utə=bədə nixə-i-mi

thou how say-COND.CVB-2sG I that=PTCL do-PTCP.PRS-1sG

'I do however you say.'

[WH]

(Baek 2016:201)

Of twenty-six WH-correlative constructions, ten have some kind of conditional morphology. Of these, only one, Tibetan, has both the definite and universal readings, which suggests that either languages tend to eliminate conditional morphology when they grammaticalize the definite interpretation, or the presence of conditional morphology makes the development of this interpretation less likely. Both alternatives seem equally likely to us. Notice that none of the Indo-European languages use conditional morphology in correlatives, which may have to do with the availability of asyndetic conditionals in the early stages of these languages; see $\S 4.2$.

5.5. INTERROGATIVE-INDEFINITE AFFINITY. In addition to the typological generalization in $\S 5$, our analysis predicts another typological tendency. For wH-correlatives to develop according to our scenario, the language must allow the licensing of the indefinite reading of interrogatives in conditional contexts in the first place. At the same time, these languages should not be languages of the type where interrogatives are simply identical to indefinites in all contexts: if they were, there would be no way to distinguish correlatives from parataxis (not necessarily of the conditional type) and, hence, little potential for grammaticalization. ${ }^{45}$ In other words, languages with wH-correlatives should also be of the type that Gärtner (2009) labels [\% $\mathrm{i}=\mathrm{i}]$, that is, languages with a 'nonrobust ambiguity' between interrogatives and indefinites-Hamblin indefinites. Of course, it is conceivable that this ambiguity may disappear in the history of the language after correlatives have already grammaticalized, so it does not have to be a universal; but one can still expect a rather strong tendency.

The tendency is generally confirmed. Of the twenty-four wH-correlative constructions (excluding Basque and Old Hungarian; see §5.3), nineteen are found in languages

\footnotetext{
${ }^{45}$ We do have one possible example of such a grammaticalization in our sample: Middle Russian, according to the interpretation of Mitrenina (2010). However, the scenario of the evolution of correlatives in such languages is in fact closer to the DEM-correlative type in our typology. In any case, the number of such languages seems to be very small.
} 
that can be classified as $[\% \mathrm{i}=\mathrm{i}]$ with a high degree of confidence. For the majority of the remaining languages, we simply have no reliable data on the licensing of interrogatives as indefinites. There are only two exceptions: Ossetic (Iranian) and Hungarian (Uralic). However, Ossetic seems to disallow wH-indefinites in conditionals on purely formal grounds (competition for the same preverbal position as the conditional subordinator), which makes Hungarian the only real exception. For Ossetic, furthermore, there is some indirect evidence that it used to be $\mathrm{a}[\% \mathrm{i}=\mathrm{i}]$ language in the past (the series of negative pronouns). Hence, the generalization is almost exceptionless.

5.6. Summary. In this section, we have shown that the three typological predictions that follow from the proposed diachronic scenario are confirmed. First, there is a strong connection between wH-correlatives and the universal reading, whereas the definite reading is often not available to such constructions. This is in a clear contrast to DEMcorrelatives, which always have a definite interpretation and in fact never (in our sample) have a universal reading without special marking. Second, wH-correlatives often involve conditional morphology - in one case even when the interpretation is not universal, as in Tibetan. This case apart, we tentatively suggested that languages tend to give up the conditional marking when they grammaticalize the definite reading (or that the conditional marking inhibits the development of the definite reading). Third, there is a link between WH-correlatives and the licensing of indefinite readings of interrogatives in conditional contexts (Hamblin indefinites). All three facts follow directly from our diachronic proposal but are not explained by competing approaches.

6. ConClusion. In this article, we have proposed that wH-correlatives have a different origin from DEM-correlatives. While DEM-correlatives, as standardly assumed in the literature, develop from parataxis with obligatorized anaphoric coreference (lit. That girl came, I saw her), we argue that wH-correlatives develop from conditional structures that are either paratactic (asyndetic or with a coordinator) or explicitly marked as conditionals, where the interrogative gets the indefinite interpretation by virtue of being bound by the conditional operator (lit. If some girl came, I saw her). Such conditional structures develop into correlatives through a cline of anaphoric integration, which makes coreference obligatory. This yields a conditional-like, universal reading of the correlative structure, which in many languages is the only one found in wH-correlative structures. In other languages, the development goes further and yields a definite reading.

This predicts a semantic asymmetry between the two types of correlatives: the definite reading is expected to be the only or basic reading for DEM-correlatives, while WHcorrelatives are expected to have the universal interpretation as the only or basic reading. Using a typological sample that includes most languages where correlatives have been sufficiently described in the literature, we confirmed this hitherto unnoticed typological generalization. In many languages with wH-correlatives, the definite reading is altogether unavailable, and there are no languages that only have the definite reading. In contrast, DEM-correlatives always have the definite reading, and in our sample in fact NEVER have the universal reading except in the presence of special operators such as modal or habitual markers.

Our study shows the value of careful semantic analysis in diachronic studies. It also shows that correlatives are complex and many-faceted objects. This has implications for the synchronic study of correlatives as well. Much influential work on correlatives has focused on Hindi. But as our study shows, there is a lot of diversity in correlatives, and we cannot expect syntactic and semantic analyses to generalize across languages, especially not across the division between DEM- and WH-based correlative structures. 


\section{REFERENCES}

ANDrews, AVERy. 1975. Studies in the syntax of relative and comparative clauses. Cambridge, MA: MIT dissertation. Online: http://hdl.handle.net/1721.1/27379.

ArseniJEVIĆ, Boban. 2009. \{Relative \{conditional \{correlative clauses\}\}\}. In Lipták 2009a, $131-56$.

Asher, Nicholas, and Alex Lascarides. 2003. Logics of conversation. Cambridge: Cambridge University Press.

Authier, Gilles. 2009. Grammaire kryz (Langue caucasique d'Azerbaïdjan, dialecte d'Alik). Leuven: Peeters.

Baek, Sangyub. 2016. Tungusic from the perspective of areal linguistics. Sapporo: Hokkaido University dissertation.

Bauer, Jaroslav. 1972. Phénomènes centraux et périphériques dans l'évolution du système syntaxique de la langue tchèque. Syntactica slavica: Vybrané práce ze slovanské skladby, vol. 1, 35-46. Brno: Universita J. E. Purkyně.

Belyaev, Oleg I. 2014. Korreljativnaja konstrukcija v osetinskom jazyke v tipologičeskom osveščenii [Ossetic correlatives in typological perspective]. Moscow: Lomonosov Moscow State University dissertation.

Belyaev, Oleg, and Dag Haug. 2014. Pronominal coreference in Ossetic correlatives and the syntax-semantics interface. Proceedings of the LFG '14 Conference, 89-109. Online: http://web.stanford.edu/group/cslipublications/cslipublications/LFG/19/papers /lfg14belyaevhaug.pdf.

BENDE-FARKAS, ÁGNES. 2015. The landscape of universal quantification in Old Hungarian. Acta Linguistica Hungarica 62(3).223-61. Online: https://www.jstor.org/stable/26191 778.

Bhatt, Rajesh. 2003. Locality in correlatives. Natural Language and Linguistic Theory 210.485-541. DOI: 10.1023/A:1024192606485.

Birnbaum, Henrik. 1974. On Old Russian and Old Scandinavian legal language: The Russkaja pravda and medieval Swedish law. On medieval and renaissance Slavic writing, ed. by Henrik Birnbaum, 234-59. The Hague: Mouton.

BitTner, Maria. 2001. Topical referents for individuals and possibilities. Proceedings of Semantics and Linguistic Theory (SALT) 11.36-55. DOI: 10.3765/salt.v11i0.2854.

BJorkman, Bronwyn Moore. 2013. A syntactic answer to a pragmatic puzzle: The case of asymmetric and. Syntax and its limits, ed. by Raffaella Folli, Christina Sevdali, and Rob Truswell, 391-408. Oxford: Oxford University Press. DOI: 10.1093/acprof:oso/97 80199683239.003.0019.

Borgman, Donald M. 1990. Sanuma. Handbook of Amazonian languages, vol. 2, ed. by Desmond C. Derbyshire and Geoffrey K. Pullum, 15-248. Berlin: De Gruyter.

Brasoveanu, Adrian. 2008. Uniqueness effects in correlatives. Proceedings of Sinn und Bedeutung 12.47-65. DOI: 10.18148/sub/2008.v12i0.575.

Cable, Seth. 2009. The syntax of the Tibetan correlative. In Lipták 2009a, 195-222.

Cinque, Guglielmo. 2005. A note on verb/object order and head/relative clause order. University of Venice Working Papers in Linguistics 15.49-104.

Cinque, Guglielmo. 2012. Five notes on correlatives. Typological studies: Word order and relative clauses, 208-17. London: Routledge.

Creissels, Denis. 2009. Les relatives corrélatives: Le cas du malinké de Kita. Langages 174.39-52. DOI: 10.3917/lang.174.0039.

Culicover, Peter W., and Ray Jackendoff. 1997. Semantic subordination despite syntactic coordination. Linguistic Inquiry 28(2).195-217. Online: https://www.jstor.org/stable 14178974.

Dayal, VeneEta. 1995. Quantification in correlatives. Quantification in natural languages, vol. 2, ed. by Emmon W. Bach, Eloise Jelinek, Angelika Kratzer, and Barbara H. Partee, 179-205. Dordrecht: Kluwer.

DE VRIES, MARK. 2002. The syntax of relativization. Amsterdam: University of Amsterdam dissertation. Online: https://hdl.handle.net/11245/1.192704.

DelbrǘcK, Berthold. 1900. Grundriss der vergleichende Grammatik der indogermanischen Sprach, vol. 5: Vergleichende Syntax der indogermanischen Sprachen, part 3. Strassburg: Karl J. Trübner. 
DemiroK, ÖMER. 2017. A compositional semantics for Turkish correlatives. West Coast Conference on Formal Linguistics (WCCFL) 34.159-66. Online: http://www.lingref.com /cpp/wccfl/34/paper3308.pdf.

Diewald, GABRIELE. 2002. A model for relevant types of contexts in grammaticalization. New reflections on grammaticalization: International symposium, Potsdam, 17-19 June, 1999, ed. by Ilse Wischer and Gabriele Diewald, 103-20. Amsterdam: John Benjamins.

Dryer, Matthew S. 2013. Order of relative clause and noun. The world atlas of language structures online, ed. by Matthew S. Dryer and Martin Haspelmath. Leipzig: Max Planck Institute for Evolutionary Anthropology. Online: http://wals.info/chapter/90, accessed April 12, 2019.

Dumestre, GÉRARD. 2003. Grammaire fondamentale du bambara. Paris: Éditions Karthala.

ECKARDT, REGINE. 2006. Meaning change in grammaticalization. Oxford: Oxford University Press.

ECKARDT, Regine. 2011. Semantic reanalysis and language change. Language and Linguistics Compass 5(1).33-46. DOI: 10.1111/j.1749-818X.2010.00260.x.

Gärtner, Hans-Martin. 2009. More on the indefinite-interrogative affinity: The view from embedded non-finite interrogatives. Linguistic Typology 13.1-37. DOI: 10.1515 /LITY.2009.001.

Givón, TALmy. 2009. The genesis of syntactic complexity: Diachrony, ontogeny, neuro-cognition, evolution. Amsterdam: John Benjamins.

Grosu, Alexander, and Fred Landman. 1998. Strange relatives of the third kind. Natural Language Semantics 6(2).125-70. DOI: 10.1023/A:1008268401837.

Hackstein, Olav. 2004. Rhetorical questions and the grammaticalization of interrogative pronouns as conjunctions in Indo-European. Per aspera ad asteriscos: Studia indogermanica in honorem Jens Elmegård Rasmussen sexagenarii Idibus Martiis anno MMIV, ed. by Adam Hyllested, Anders Richard Jørgensen, Jenny Helena Larsson, and Thomas Olander, 167-86. Innsbruck: Innsbrucker Beiträge zur Sprachwissenschaft.

Hahn, E. Adelaide. 1946. The origin of the relative kwi- kwo-. Language 22(2).68-85. DOI: $10.2307 / 410340$.

Hahn, E. Adelaide. 1949. The non-restrictive relative in Hittite. Language 25(4).346-74. DOI: $10.2307 / 409862$.

Haiman, John. 1983. Iconic and economic motivation. Language 59(4).781-819. DOI: $10.2307 / 413373$.

Hale, Kenneth L. 1976. The adjoined relative clause in Australia. Grammatical categories in Australian languages, ed. by R. M. W. Dixon, 78-105. Canberra: Australian Institute of Aboriginal Studies.

Harris, Alice C. 1994. On the history of relative clauses in Georgian. Non-Slavic Languages of the USSR: Papers from the fourth conference, ed. by Howard I. Aronson, 130-42. Columbus, OH: Slavica.

Haspelmath, Martin. 1997. Indefinite pronouns. Oxford: Oxford University Press.

Haudry, JeAn. 1973. Parataxe, hypotaxe et corrélation dans la phrase latine. Bulletin de la société de linguistique de Paris 68(1).147-86.

Haug, Dag Trygve Truslew. 2013. Partial dynamic semantics for anaphora: Compositionality without syntactic coindexation. Journal of Semantics 31(4).457-511. DOI: 10.1093/jos/fft008.

Haug, Dag Trygve Truslew. 2016. PIE * $k^{w} i-/ k^{w} O-:$ Interrogative, indefinite or both? Tavet tat satyam: Studies in honor of Jared S. Klein on the occasion of his seventieth birthday, ed. by Andrew Miles Byrd, Jessica DeLisi, and Mark Wenthe, 86-100. Ann Arbor, MI: Beech Stave.

Heine, Bernd, and Tania Kuteva. 2003. On contact-induced grammaticalization. Studies in Language 27(3).529-72. DOI: 10.1075/sl.27.3.04hei.

Heine, Bernd, and Tania Kuteva. 2006. The changing languages of Europe. Oxford: Oxford University Press.

HENDERY, RACHEL. 2012. Relative clauses in time and space. Amsterdam: John Benjamins.

Hermann, Karl Friedrich. 1850. Disputatio de protasi paratactica. Göttingen: Officina Academica Dieterichiana.

Higginbotham, James. 1984. English is not a context-free language. Linguistic Inquiry 15(2).119-26. Online: https://www.jstor.org/stable/4178381. 
Hock, Hans Heinrich. 2008. Dravidian syntactic typology: A reply to Steever. Annual review of South Asian languages and linguistics, ed. by Rajendra Singh, 163-98. Amsterdam: Mouton de Gruyter. DOI: 10.1515/9783110211504.2.163.

Hopper, Paul J., and Elizabeth Closs Traugott. 2003. Grammaticalization. 2nd edn. Cambridge: Cambridge University Press.

Huggard, Mattyas. 2015. Wh-words in Hittite: A study in syntax-semantics and syntaxphonology interfaces. Los Angeles: University of California, Los Angeles dissertation. Online: https://escholarship.org/uc/item/1gb9f3dg.

Kadmon, Nirit. 1990. Uniqueness. Linguistics and Philosophy 13(3).273-324. DOI: 10 .1007/BF00627710.

Kamp, Hans. 1981. A theory of truth and semantic representation. Formal methods in the study of language, ed. by Jeroen A. G. Groenendijk, Theo M. V. Janssen, and Martin B. J. Stokhof, 277-322. Amsterdam: Mathematical Centre.

KartTunen, Lauri. 1977. Syntax and semantics of questions. Linguistics and Philosophy 1(1).3-44. DOI: 10.1007/BF00351935.

KEENAN, EDWARD L. 1985. Relative clauses. Language typology and syntactic description, vol. 2: Complex constructions, ed. by Timothy Shopen, 141-70. Cambridge: Cambridge University Press.

Keshet, Ezra. 2013. Focus on conditional conjunction. Journal of Semantics 30(2).21156. DOI: $10.1093 /$ jos/ffs011.

Kratzer, Angelika, and Junko Shimoyama. 2002. Indeterminate pronouns: The view from Japanese. The proceedings of the Third Tokyo Conference on Psycholinguistics (Hituzi Syobo), ed. by Yukio Otsu, 1-25.

Kroll, WiLhelm. 1910. Der lateinische Relativsatz. Glotta 3(1).1-18. Online: https://www .jstor.org/stable/40264752.

Lehmann, Christian. 2015. Thoughts on grammaticalization. 3rd edn. Berlin: Language Science. DOI: 10.17169/langsci.b88.98.

LipTÁK, ANIKó. 2008. On the correlative nature of Hungarian left-peripheral relatives. Dislocated elements in discourse: Syntactic, semantic, and pragmatic perspectives, ed. by Benjamin Shaer, Philippa Cook, Werner Frey, and Claudia Maienborn, 398-430. London: Routledge.

LiptÁK, ANIKó (ed.) 2009a. Correlatives cross-linguistically. Amsterdam: John Benjamins.

LiPTÁK, ANIKó. 2009b. The landscape of correlatives: An empirical and analytical survey. In Lipták 2009a, 1-48.

Luján, Eugenio R. 2009. On the grammaticalization of $* k^{w} i / k^{w} O$ in Proto-Indo-European. Grammatical change in Indo-European languages, ed. by Vit Bubenik, John Hewson, and Sarah Rose, 221-36. Amsterdam: John Benjamins.

MaKeEVA, NAdEŽDA V. 2013. Kommunikativnye strategii i korreljativnaja konstrukcija v jazyke kla-dan i drugix južnyx mande [Communicative strategies and correlatives in Kla-Dan and other Southern Mande languages]. Voprosy jazykoznanija 2013(1).77-94. Online: http://vja.ruslang.ru/en/archive/2013-1/77-94

Milsark, GARY L. 1974. Existential sentences in English. Cambridge, MA: MIT dissertation.

Mithun, Marianne. 2012. Questionable relatives. Relative clauses in languages of the Americas, ed. by Bernard Comrie and Zarina Estrada-Fernández, 269-300. Amsterdam: John Benjamins.

Mitrenina, Olga. 2010. Correlatives: Evidence from Russian. Formal studies in Slavic linguistics: Proceedings of Formal Description of Slavic Languages 7.5, ed. by Gerhild Zybatow, Philip Dudchuk, Serge Minor, and Ekaterina Pshehotskaya, 135-52. Frankfurt am Main: Peter Lang.

Muskens, ReinhaRd. 1996. Combining Montague semantics and discourse representation. Linguistics and Philosophy 19.143-86. DOI: 10.1007/BF00635836.

Nikitina, Tatiana. 2012. Clause-internal correlatives in Southeastern Mande: A case for the propagation of typological rara. Lingua 122(4).319-34. DOI: 10.1016/j.lingua.2011 .12 .001 .

NordLINGER, RACHEL. 2006. Spearing the emu drinking: Subordination and the adjoined relative clause in Wambaya. Australian Journal of Linguistics (Special issue: Subordination in Australian Aboriginal languages) 26(1).5-29. DOI: 10.1080/0726860050053 1610 . 
Partee, Barbara H. 1991. Topic, focus and quantification. Proceedings of Semantics and Linguistic Theory (SALT) 1.159-88. DOI: 10.3765/salt.v1i0.2918.

Paul, Hermann. 1909. Prinzipien der Sprachgeschichte. 4th edn. Halle: Niemeyer.

Polinsky, Maria. 2015. Tsez syntax. Cambridge, MA: Harvard University, Ms. Online: https://ling.auf.net/lingbuzz/002315, accessed May 28, 2018.

Probert, Philomen. 2006. Clause boundaries in Old Hittite relative sentences. Transactions of the Philological Society 104(1).17-83. DOI: 10.1111/j.1467-968X.2006.00165.x.

Pullum, Geoffrey K. 1985. On two recent attempts to show that English is not a CFL. Computational Linguistics 10(3-4).182-86. Online: https://www.aclweb.org/anthology /J84-3003.

Rebuschi, Georges. 2009. Basque correlatives and their kin in the history of Northern Basque. In Lipták 2009a, 81-130.

SCHMERLING, SuSAN. 1975. Some remarks on symmetric and asymmetric conjunctions. Syntax and semantics, vol. 3: Speech acts, ed. by Peter Cole, 211-32. New York: Academic Press.

Srivastav, Veneeta. 1991. The syntax and semantics of correlatives. Natural Language and Linguistic Theory 9(4).637-86. DOI: 10.1007/BF00134752.

Wegener, Philipp. 1874. Der lateinische Relativsatz. Treptow an der Rega: Fr. Lehfeldt.

Wessén, Elias. 1965. Svensk språkhistoria 3: Grundlinjer til en historisk syntax. Stockholm: Almqvist \& Wiksell.

YANOVICH, IGOR. 2005. Choice-functional series of indefinite pronouns and Hamblin semantics. Proceedings of Semantics and Linguistic Theory (SALT) 15.309-26. DOI: 10 $.3765 /$ salt.v15i0.2921.

\section{Belyaev}

Department of Theoretical and Applied Linguistics

Lomonosov Moscow State University

Leninskie gory, 1st Humanities Building

119991 GSP-1 Moscow, Russia

[belyaev@ossetic-studies.org]

Haug

Department of Linguistics and Nordic Studies

University of Oslo

PO Box 1102 Blindern

N-0317 Oslo, Norway

[daghaug@ifikk.uio.no]
[Received 23 May 2019; revision invited 27 October 2019; revision received 24 December 2019; accepted pending revisions 10 April 2020; revision received 11 June 2020; accepted 15 June 2020] 